Born this way? Is kink a sexual orientation or a preference?

by

\title{
Caitlin Hart
}

A thesis submitted to the Faculty of Graduate and Postdoctoral Affairs in partial fulfillment of the requirements for the degree of Master of Arts

in

Women's and Gender Studies

Pauline Jewett Institute of Women's and Gender Studies

Carleton University

Ottawa, Ontario

(C) 2020, Caitlin Hart 


\begin{abstract}
What does it mean to be kinky? Is it a deviant tendency, a recreational activity, a deep-seated desire or an integral part of one's subjectivity? In this thesis, I address the latter theory. Specifically, I explore the question of whether kink - for some people - should be considered a sexual orientation. I will begin by surveying different definitions of sexual orientation, considering what the term means in various socio-legal contexts, and how it has tended to focus on gender preference of sexual partners. I will then analyze whether sexual orientation should be a more inclusive term to encompass sexual practices. Finally, using data collected from interviews I will present how kink practitioners themselves categorize their activities with relation to sexual orientation. Is kink something that people are born with? Or something they develop?
\end{abstract}




\section{Acknowledgments}

This thesis has been well over three years in the making and has encompassed arguably one of the most difficult times in my life. I began my masters just after my father's diagnosis with melanoma, which I would not recommend to anyone. Doing a master's degree is hard enough in itself but dealing with the illness of one of my favourite people at the same time proved to be a Herculean feat.

I am indebted to the team I had around me, namely my supervisor Ummni Khan who from day one provided support when I needed it the most and was the voice of reason when I needed to take a break. Her kindness is something I will never forget.

To Lana Keon who would answer any and all questions I had, thank you. Lana helped me navigate the mine field that is university administration so that I could finish my degree, but also be compassionate to myself when needed.

Katie Bausch who was by far the best prof I could ever TA for. She provided endless and unwavering support to her teaching team and always made sure we never did too much work.

Pat Gentile, you will go to any lengths to help students and I can't thank you enough. If all departments had a grad advisor like you the world would be a much better place and students would be a lot less overwhelmed.

There were so many times I really did not think I would finish. I cannot express how thankful I am to have the support system I do of friends, colleagues and family.

Thank you to my co-hort who made me love coming to class and who helped me survive course work. Emily, Kat, Wilder and Jess, you guys made my first year better than I could have expected. 
Thank you to Kira Smith, who has been my rock and first call in emergencies for 8 years. She has been there for me at my worst and always able to offer insight when I can barely see the next day. She is truly my other half.

To Max and Amanda, thank you for letting me be your third roommate. My mom said it best when she said that you guys treat me so well.

To the Ummni Fan Club: Pj, Delph and Rachel. You all have provided so much help not only to my research but also to my sanity. I hope we always have movie nights with Hawaiian Pizza. I can’t wait to see us all become badass sex researchers.

Huge thank you to my roommates Andy and Pj. My home has always been my sanctuary and you guys have made it heaven.

To all my theatre friends you made me laugh and remember fun at times when I forgot how to have fun. Stay loud and weird!

To my favourite band the Dirty Nil for making the best record during the shittiest time for me. Thank you for kicking ass and fueling me with rock 'n' roll when I felt the most down.

To Sick Boy Podcast for making me laugh and cry and mostly for preparing me to deal with death.

To my brother Tim, for exemplifying to importance of not cutting corners and that attention to detail is crucial. Thank you for offering a listening ear when I needed it and for instilling in me that everything is clearer after a good walk. It is because of this that I to this day will go for walks to sort out the noise in my head. I hope that our friendship will last a lifetime of good beer, Lego and very long walks.

Mom, you have shown me that there are no lengths you won't go for someone you love. You were unbreakable when I felt like I was going to crumble and always supported any play, 
piece of writing or creative outlet I have embarked on. I might be an adult, but I do still very much need my mom sometimes and I'm glad that person is you.

To my father, who will not get to read this thesis or get to see me graduate. He was always my cheerleader, even when I went off on my own path. I could not have thought that doing a thesis on kink was possible without his knack for breaking convention and his encouragement for being different. I know he has been with me every step of the way, even after he left this earth. This thesis and this degree is for him. 


\section{Table of Contents}

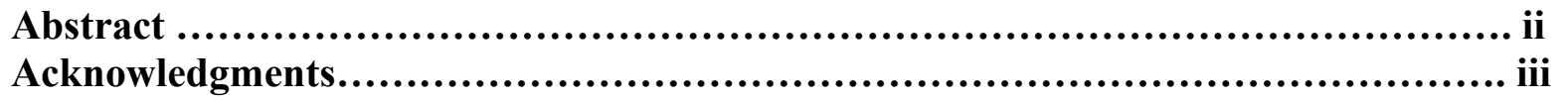

Chapter 1: Introduction..............................................................1

Chapter 2: Literature Review...........................................................8

I. Psych Studies of kink...............................................

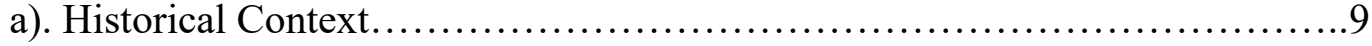

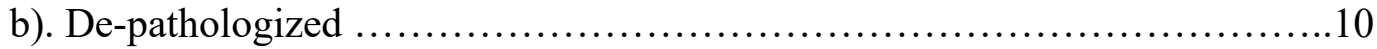

II. Anthropological /Sociological Studies of kink............................14

a). Ethnographies...................................................... 14

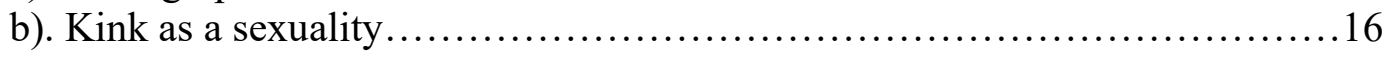

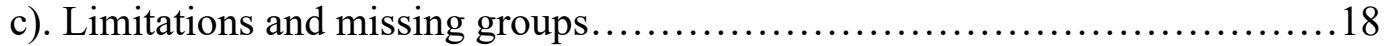

III. Sexual Orientation...................................................... 20

a). Historical Understanding .................................................

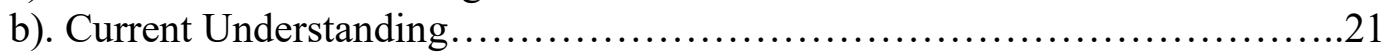

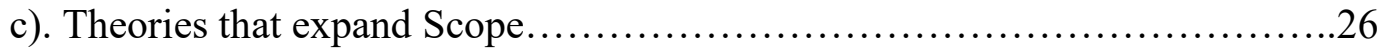

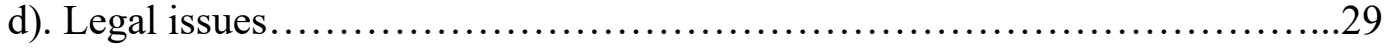

Chapter 3: Methods.......................................................................34

I. Recruitment of Interviewees.......................................... 34

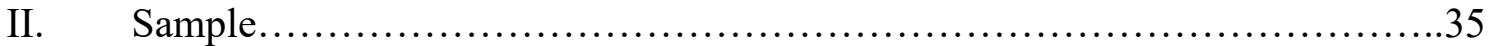

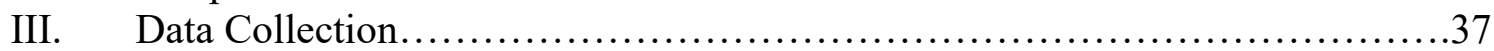

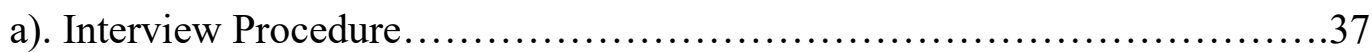

b). Semi Structured Interviews......................................... 38

IV. Data Analysis....................................................... 39

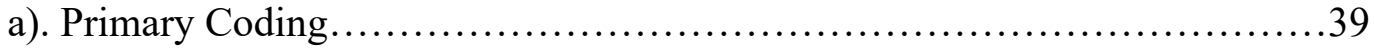

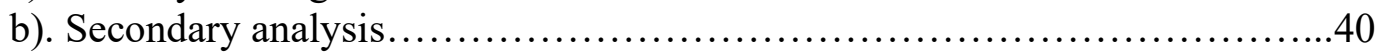

V. Ethical Considerations...............................................41

a) Insider/Outsider.................................................... 41

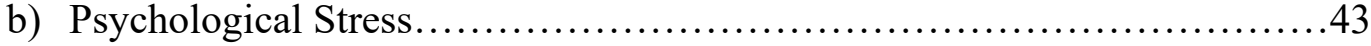

c) Confidentiality ..................................................44

Chapter 4: Results....................................................................45

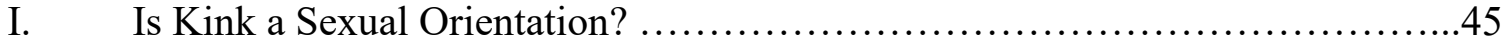

a). Born this way/Immutability......................................45 


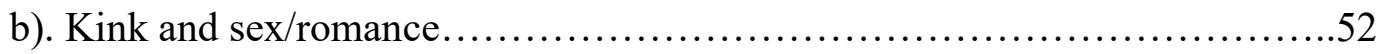

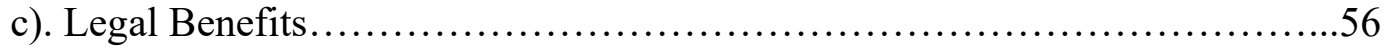

II. Kink Culturally......................................................58

a). Kink communities................................................... 58

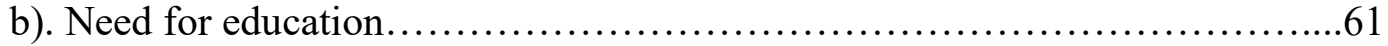

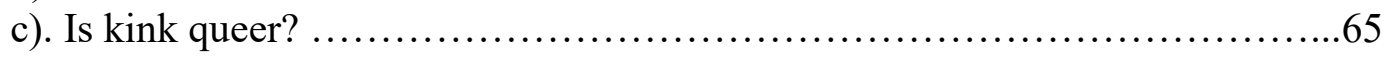

III. Trans Perspectives....................................................68

a). Perceived Discrimination................................................... 68

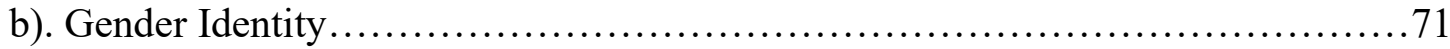

Chapter 5: Conclusion .................................................. 74

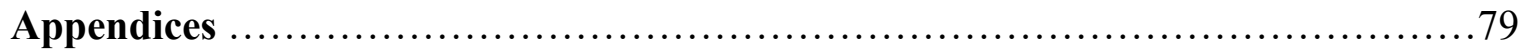

Appendix A: Participants Demographic Data......................................79

Appendix B: Recruitment Poster.................................................8

Appendix C: Interview Questions..................................................81

Appendix D: Informed Consent Form $. . . \ldots \ldots \ldots \ldots \ldots \ldots \ldots \ldots \ldots \ldots \ldots \ldots \ldots \ldots \ldots \ldots \ldots \ldots . . . \ldots 2$

Appendix E: Oral Consent Script................................................85

Appendix F: Fetlife Communications..................................................87

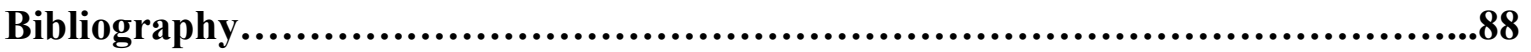




\section{Chapter 1: Introduction}

The terms sadism, masochism, sadomasochism, BDSM (which stands for bondagediscipline sado-masochism) and kink have contested meanings within various branches of society. In this thesis, I will use "kink" as an umbrella term to signify all the aforementioned concepts. According to Miriam Webster, kink is defined as unconventional sexual tastes or behaviours. Historically, kink-associated activities and identities were constructed as pathologies by sexologists and included as "sexual disorders" in the Diagnostic Statistics Manual (DSM). While Kraftft-Ebing (1965) framed kink as deviant, recent sociologists have begun to frame kink as an interest that can create community and a sense of identity (Bezreh et al., 2015; Iannotti, 2014; Khan, 2015; Newmahr, 2011). The work of Weinberg et al. (1984) spurred a movement to further de-pathologize kink and recognize it as a social practice that is not necessarily deviant. Weinberg et al. (1984) spent eight years interviewing and observing participants about their experiences with kink, which at the time was unprecedented. This gave more insight to the actual behaviours and experiences of kink practitioners outside of the lens of a psychiatric diagnosis.

There is a substantial amount of research that has challenged the negative portrayal of kink. From a neutral or positive vantage point, kink can be defined as the appearance of power of one partner over the other and unconventional sensual, erotic and/or sexual activities (Moser \& Kleinplatz, 2006; Rehor, 2015). Such literature has mostly focused on de-pathologizing kink or creating ethnographies of kink communities (Dymock, 2012; Moser \& Kleinplatz, 2006; Newmahr 2010 \& 2011; Weiss, 2011). This thesis will contribute to challenging anti-kink ideologies by exploring the possibility of framing kink as a sexual orientation. In particular, I 
will evaluate whether framing kink as a sexual orientation accurately reflects the perspective of kink practitioners and whether such a framing would advance the kink community's socio-legal interests. Currently, the standard definition of sexual orientation refers to heterosexual, homosexual, bisexual and sometimes pansexual as possible identities that fit under the definition. More recently, some have argued that asexuality and demisexuality should be included within the broad rubric of sexual orientation (Brotto \& Yule, 2017). In public discourse, kink is not seen as a viable sexual orientation.

This thesis will seek to explore the potential benefits and detriments if kink were to be considered a sexual orientation. Some scholars see kink as a form of serious leisure or community practice that may overlap but is conceptually separate from sex (Newmahr, 2011; Sloan, 2015; Simula, 2019a; Weiss, 2011). There is already a small amount of scholarship that seeks to expand the definition of sexual orientation to include kink, as well as polyamory, as potentially new sexual orientations (Klesse, 2014; Miletski, 2017; Moser, 2016; Tweedy, 2011). Some scholars have argued that considering kink a sexual orientation would help reduce stigma and potentially offer legal benefits and protections to those who identify as kinky (Bezreh et al., 2015; Klesse, 2014; Tweedy, 2011). According to recent statistics, those who identify as kinky face discrimination in the form of job loss, child custody battles, as well as other forms of verbal harassment (Bezreh et al., 2015; Moser \& Kleinplatz, 2006; Meeker, 2013; Stiles \& Clark, 2011; Tweedy, 2011). Certain kinky activities are penalized as assault for causing physical harm under consent to harm laws, despite exceptions made for contact sports (Luksic, 2015). Legal protections similar to those given to other LGBTQ+ identities could help protect kinky individuals from such discrimination and harassment. 
Previous research and methodologies that address kink communities or those who identify as kinky tend to approach the area from a psychological perspective or from an outsider ethnographic approach. For example, kink practitioners have been studied to determine if their personality traits are different from non-kink practitioners and if their overall mental well-being is better or worse than non-kink populations (Khan, 2015; Pascoal, 2015; Ritchers et al., 2008; Wismeijer et al., 2013) For the purpose of this thesis, I have decided to use qualitative interview data and grounded theory, which involves finding trends within the data, instead of applying an existing theoretical framework to the data (Charmaz, 2006; Faccio et al., 2014). Grounded theory involves using comparative distinctions to find similarities within the data (Charmaz, 2006; Faccio et al., 2014; Tripodi, 2017). The process of grounded theory is nonlinear and involves continuously analysing data throughout the writing process (Charmaz, 2006). Further, this involves constructing theories from past and present interactions with other theories, people and lived experience, rather than discovering them (Charmaz, 2006).

This thesis will not focus on psychological diagnosis but instead on lived experiences of those who self-identify as kinky. Rather than theorizing the benefits or drawbacks of framing kink as a sexual orientation on an abstract level, this thesis will ask those with lived experience and kink identifications what they think. Past research has more often centred around kink that takes place in public spaces or within therapeutic or psychological practices, leaving out kinky folks who fit into neither population. This skews the results of the data to overemphasize the experiences of often white, middle-to-upper-class kink practitioners (Bauer, 2008; Dymock, 2012; Newmahr, 2011; Pascoal et al., 2015; Weiss, 2011). Therefore, this thesis seeks to avoid reproducing these methods and aims to have more diverse voices and kink practitioners who do not participate regularly (or at all) in public kink-related events or spaces. 
In my study, seven participants were asked about their current involvement and relationship with kink, as well as their kink origin story. These experiences were analyzed to uncover common themes with regards to discrimination experienced and possible areas that could be improved by better legal and/or social policies. In addition, the link between sex and kink was examined, as many participants cited varying experiences and opinions regarding whether or not they considered kink to be sexual and/or romantic.

Further, this thesis will examine the current definitions of sexual orientation and sex. By analyzing both definitions, this thesis will explore the possibility that both definitions need to be expanded and broadened to encompass more diverse lived experiences and identities. Moreover, this thesis asks whether the phrase "sexual orientation" should be replaced with the broader term "sexuality." The current criteria and stipulations regarding sexual orientation will be examined to better understand how we currently define something as a sexual orientation. Further, the theory and research behind sexual fluidity will be considered in contrast to the notion that sexual orientation is fixed and immutable. I will draw on research that suggests sexual desires and orientations are fluid and change over the course of a lifetime (Diamond, 2008, 2012 \& 2016; Katz-Wise, 2015; Wilton, 2004). The theory of sexual fluidity will thus be used to provide a more expansive definition that recognizes the evolving nature of sexual orientation for many people. Overall, this thesis will add to current literature that advocates for the definition of sexual orientation to be expanded and include more preferences and identities.

This dissertation will begin with a review of existing literature on kink. Chapter two will examine the evolution of psychological perspectives on kink and its categorization as a sexual deviance, to a paraphilic disorder, to the current understanding of kink as a paraphilia that may or may not be a disorder. This chapter will then explore existing anthropological and sociological 
studies on kink. These studies provide the framework that kink can be potentially an integral part of someone's sexuality, as well as a community unto itself. Finally, this chapter will review how the concept of sexual orientation was born and how it has evolved to the present day.

Chapter 3 will explain the methods used for the purpose of this research. In this chapter, I will review recruitment strategies for gaining interview participants. Following this, I will review the questions asked in interviews, as well as interview procedures. Next, I will discuss the data that was gathered during the interview process. This will include details of the participants (see Appendix A for participant demographics). Specifically, this will include the methods for analysing the data through the process of transcribing, coding and secondary analysis. Finally, the ethical considerations to ensure both the safety and confidentiality of participants will be discussed.

Chapter 4 will detail the results of participant interviews. In these chapters, common themes and theories that emerged will be detailed. For the purpose of clarity, these chapters will be divided into broad themes. While many themes emerged through interviews, for the purpose of this study, only those that directly relate to the main research question could be included. To put these themes into context, I will relate back to the data gained through studies referenced in Chapter 2.

The first section will discuss the main research question of kink being considered a sexual orientation. This section will begin by reviewing participant responses that surrounded the theme that they were born with an interest in kink. This section will detail the kink origin stories of participants, including early fantasies or desires. Further, participant definitions of sex and sexual orientation will be outlined to add further context. Next, participants' answers to the question of whether or not kink should be considered a sexual orientation will be outlined. To 
add further context, the relationship dynamics between participants and their kink partners will be explained. Finally, this section will explore the common theme of legal benefits as impetus for kink being considered a sexual orientation.

The second section will discuss the benefits and detriments of considering kink a sexual orientation from a cultural standpoint. This section will begin by examining the community aspect of kink for some participants. This will include the acquisition of skills and will directly compare participants' responses to Staci Newmahr's theory that kink is serious leisure. Next, the need for better resources and education will be examined as a potential benefit for kink being considered a sexual orientation. Participants' experiences with bad kink partners and negative perception from the public will be used to illustrate this point. The final component will examine the question of if kink should be considered queer. Participants generally felt that a negative consequence to kink being a sexual orientation would be equating the struggles and historic violence faced by the LGBTQ+ community with that of kink practitioners. Therefore, while there were some cultural benefits outlined surrounding education and resources, most participants felt that kink did not fit into the same framework as sexual orientation culturally.

The final section will focus on trans perspectives in this study. Specifically, this section will focus on the difference between cis and trans participants in relation to discrimination faced for being a kink practitioner. Through the interview process, it was found that trans participants generally felt less discrimination on the basis of their kinky identity. Overall, trans participants said they felt far more discrimination based on their trans identity. These findings will be compared to cis participants who felt, on average, greater discrimination due to their kinky identity. Finally, this chapter will explore how trans participants' kink identity interacts with their gender identity and how kink helped them discover their trans identity. Previous studies 
(Bauer, 2008; Simula, 2012) have found that kink can be a useful practice for exploring gender identity. This conclusion was supported in this study. These findings provided useful insight into how trans participants defined sexual orientation and ultimately added context to the main research question.

Chapter 5 will outline the conclusions drawn from this study. While this study was a small sample of kink practitioners, I will examine some key points that could be used for further research. These points include that there is a need for more research on the lived experiences of kink practitioners, especially outside of commercial spaces. Additionally, there is a lack of diversity in most studies on kink, specifically with regards to race and trans folks. Further from the main research question, I will suggest that more research into re-framing the concept of sexual orientation could be useful with regards to many other sexual interests outside of kink. 


\section{Chapter 2: Literature Review}

This section will cover the existing research and literature on kink that I reviewed, which provides the broader context to considering kink as a sexual orientation. This chapter will be divided into three parts: psychological studies of kink, anthropological/sociological studies of kink, and studies on sexual orientation. In the first section, I will review early studies based in sexology, which framed kink as a sexual deviance that needed to be cured. Next, I will cover scholarship that sought to de-pathologize kink and have it considered to be a normal part of human sexuality.

In the second section, I will explore the anthropological/sociological studies in kink. This section will begin with an analysis of existing ethnographies of kink communities. After this, I will review literature that frames kink as a sexual identity and, in some instances, an orientation. The final part of this section will highlight the limitations and missing groups from these studies.

The third and final section in the chapter will examine literature that focuses on the concept of sexual orientation. This section will have four parts, beginning with the historical context of sexual orientation and how it was first conceptualized. The following section will explain the current understanding of sexual orientation and theories surrounding it. The third section will explore theories that expand the current scope of sexual orientation and seek to redefine it. The fourth and final section will examine the legal implication of the framing of sexual orientation. 


\section{Psych Studies of Kink}

\section{a. Historical Context}

Early sexologists Richard von Krafft-Ebing, Sigmund Freud and Havelock Ellis first researched kink as a deviant sexuality that was in opposition to the norm (Khan, 2014; Simula, 2019b). Kink was primarily researched with the purpose of finding the cause and cure, as it was labelled a 'sexual disorder' (Khan, 2014; Simula, 2019b).

Krafft-Ebing placed kink and BDSM on a spectrum, starting with spanking and fetishes to lust murder (Ritchers et al., 2008). Krafft-Ebing argued that humans are constantly at odds with their natural animal state, which is in opposition to monogamous heterosexuality (Khan, 2014). Both Freud and Krafft-Ebing argued that human sexuality was a device to be controlled and contained, lest humans succumb to their natural animal perversity (Khan, 2014; KrafftEbing, 1965; Simula, 2019b). According to Krafft-Ebing, perversity was defined as sexual activity that was outside procreative, monogamous, heterosexual sex (Khan, 2014). These scholars, in addition to British doctor Havelock Ellis, shaped how kink was approached and defined in the first part of the $20^{\text {th }}$ century. The creation of the Diagnostic Statistics Manual (DSM) cemented some of these views on kink, putting a diagnosis and criteria for sexuality that was deviant (Khan, 2014).

The DSM first categorized kink as a sexual deviation, then later under sexual disorders (Bezreh et al., 2012). Specifically, kink was categorized under the section of paraphilias, which are defined as any persistent and/or intense sexual interest that is outside of 'genital stimulation' or 'preparatory fondling' with mature and consenting partners (American Psychiatric Association, 2013). 
In 1953, homosexuality was considered a mental disorder in the DSM (American Psychiatric Association, 1953). As gay rights movements started to gain momentum in the '60s, the DSM responded by instead classifying homosexuality as a disorder only if it caused distress and classified this as "sexual orientation disturbance," and then later "ego-dystonic homosexuality" in 1980 (Keenan, 2013). This is comparable to how kink has been defined within the DSM, first starting as a sexual disorder and now as a paraphilia, only diagnosable if it causes distress in the patient (Khan, 2014 \& 2015; Keenan, 2013; Iannotti, 2014; Moser \& Kleinplatz, 2006).

The presence of kink within the DSM has been argued by some scholars and by the National Coalition for Sexual Freedom to enable discrimination against kink practitioners in both social and legal contexts (Moser \& Kleinplatz, 2006; Gemberling et al., 2015; Wright, 2010). Therefore, in response, many scholars have argued for the complete removal of kink from the DSM (Gemberling et al., 2015; Khan, 2015; Moser \& Kleinplatz, 2006; Ritcher et al., 2008; Weinberg, 2006; Weiss, 2006; Wright, 2010 \& 2017).

\section{b. De-pathologized}

In response to previous claims that BDSM and kink are explicitly linked to mental illness and violence, scholars have sought to disprove these claims. In general, the claims that an interest in kink must be due to any of the following: past abuse, mental disorders, personality disorders, criminal intent and/or sexual deviance, have for the most part been disproven (Gemberling et al., 2015; Moser \& Kleinplatz, 2006; Pascoal et al., 2015; Richters et al., 2008; Wismeijer et al., 2013; Wright, 2010). Instead, recent studies have found that, overall, kink practitioners appear to be well adjusted members of society and, in some instances, possessing psychological advantages over the general population (Khan, 2015; Gemberling et al., 2015; 
Pascoal et al., 2015). The National Coalition for Sexual Freedom's survey in 2015 on psychological functioning of BDSM practitioners found that practitioners were not more likely to have underlying mental health issues and that an interest in BDSM was not indicative of psychological disorders and/or violence (Gemberling et al., 2015). Another study found that those who practice BDSM are not more likely to exhibit signs of sexual dysfunction or difficulties than the general population and in some ways were, in fact, on average happier with their sex lives than most (Ritchers et al., 2008). It was thought that people would partake in kink due to early childhood abuse and would then try to re-enact that abuse through kink; however, this theory has been disproven in various studies that have found that there are not any significant correlations between childhood abuse and later interest in BDSM (Khan, 2015; Gemberling et al., 2015; Stiles \& Clark, 2011; Wismeijer et al., 2013; Wright, 2010).

The work of some scholarship on kink focuses on the removal of kink completely from the DSM. In the most recent edition, the DSM-V, sexual masochism and sexual sadism are still present under the section on paraphilias. A paraphilia is defined in the DSM-V as "any intense and persistent sexual interest other than sexual interest in genital stimulation or preparatory fondling with phenotypically normal, physically mature, consenting human partners" (American Psychiatric Association, 2013).

Peggy Kleinplatz and Charles Moser have written extensively on the subject of removing kink from the DSM. They argue that the paraphilia section does not reflect current understandings of sexual disorders, specifically that what constitutes normal, non-pathological sexual behaviour remains vaguely defined within the DSM (Moser \& Kleinplatz, 2006; Weinberg, 2006). Khan (2015) mentions that, in most cases, the distinction between something that is a paraphilic disorder, and therefore in need of treatment, and something that is considered 
normal is arbitrary. The current edition of the DSM, released in 2013, states that to be considered a disorder, there has to be distress around the paraphilia; however, this distinction raises many questions (Khan, 2015). As Moser explains: "The 'sexual masochist' who prefers to be whipped rather than engage in coitus has a paraphilia and the 'sexual masochist' who prefers to be whipped as foreplay to coitus is normophilic" (Moser, 2011). The main problem is the definition of distress. As journalist Jillian Keenan said, "Simply put, the DSM V will say that happy kinksters don't have a mental disorder. But unhappy kinksters do.” (2013). Keenan mentions that while to some this might seem like progress, it actually is a similar process to the DSM's treatment of homosexuality in the 1960s. Kleinplatz and Moser mention that equating a sexual interest with a psychiatric diagnosis has been used to oppress sexual minorities in the past (Moser \& Kleinplatz, 2006; Weinberg, 2006). Many scholars have contended that having sexual interests such as kink in the DSM gives license for legislation and policies to continue to discriminate against these groups (Weinberg, 2006; Weiss, 2006; Wright 2017 \& 2010).

\section{Discrimination and Kink}

In the case of BDSM, many individuals face discrimination with regards to employment, child custody, and within the criminal courts system (Bezreh et al., 2012; Gemberling et al., 2015; Meeker, 2014; Wright, 2010). BDSM practitioners experience discrimination in four distinct ways: through negative public portrayal, value diminishment, mockery or shunning, and discrimination (Brown, 2010).

A 2011 study of 73 BDSM practitioners analyzed how open with their practices they were and with whom. The study found that $38 \%$ of respondents concealed their BDSM practices from everyone who is not a part of that community and $25 \%$ only told close family and friends 
(Stiles \& Clark, 2011). This means that more than half have some level of secrecy about the BDSM practices from the majority of people in their lives. The common reasons listed for this concealment were fear of loss of job, negative effects on relationships with family and friends, and overarching stigma surrounding BDSM (Stiles \& Clark, 2011).

The first survey on Violence and Discrimination Against Sexual Minorities in 1998 showed that $87 \%$ have experienced verbal harassment and $25 \%$ have lost a job or job opportunity due to their involvement with BDSM (Iannotti, 2014). An updated version of the survey in 2008 found that $37.5 \%$ of respondents experienced some form of discrimination or harassment for their involvement in kink (Wright, 2010).

In relation to these statistics, scholars are advocating for not only the removal of kink from the DSM, but also that kink be treated like another normal aspect of sexuality (Gemberling et al., 2015; Kleinplatz 2006; Moser \& Kleinplatz, 2006; Wright, 2010). Kleinplatz (2006) further argues that non-kink practitioners could, in fact, learn from kink practitioners in terms of negotiating consent and improving sexual experiences.

Overall, the trend in current kink-related research is to use empirical and analytical arguments to debunk previous claims of kink as mental illness and to examine benefits from practising kink. The growing statistics on discrimination faced by those who practice kink is used as evidence to support arguments that kink should be removed from the DSM. Beyond removal from the DSM, many scholars are arguing that greater understanding of the psychology of kink and potential benefits can reduce stigma and increase public knowledge about a topic that is often pushed to the margins of society (Bezreh et al., 2012; Gemberling et al., 2015; Iannotti, 2014; Kleinplatz, 2006; Meeker 2014; Moser \& Kleinplatz, 2006; Wright, 2008 \& 2010). 


\section{Anthropological/Sociological Studies}

\section{a. Ethnographies}

Scholarship surrounding kink in the field of sociology builds off of the previous studies that have sought to de-pathologize kink. The following section will examine how kink has been studied from a sociological standpoint. Kink has been studied from two general approaches: 1) ethnographic studies of a particular community with a focus on the customs and practices present in that community and 2) analysis of the personal meaning and expression of kink as it relates to one's identity.

Early ethnographic studies of kink primarily focused on the gay leather communities in many major North American cities due to easier access (Simula, 2019; Weinberg, 2006). This began to change as more social constructionist models of BDSM study appeared, notably with the work of Weinberg, Williams, and Moser (1984). Through eight years of observation and interviews, Weinberg et al. were able to identify social characteristics of BDSM play (1984). The work set precedent for future ethnographies that would focus on the customs and social aspects of BDSM and kink, rather than just the psychological and diagnostic (Newmahr, 2010; Simula, 2019 a \& b; Weinberg, 2006; Weiss, 2006).

Staci Newmahr's and Margot Weiss's ethnographies focused on two communities in the United States. Newmahr's work focused on a community in upstate New York, while Weiss studied a community in the Bay Area in California. Both studies involved the researchers attending many play parties, fundraisers and dinners, observing and interviewing participants about their involvement in their kink community (Newmahr, 2010; Weiss, 2006). Newmahr's study also involved her own participation in BDSM scenes and her own interactions with her participants (2010). Both researchers found that kink was mostly a form of "serious leisure" 
(elaborated below), as opposed to a sexual orientation or identity. Other observations gained from these studies were that most participants were white, middle to upper-middle class and cisgender (Newmahr, 2010; Weiss, 2006). In these two studies, kink was not said to be a form of sexual expression or even to count as sex amongst participants (Newmahr, 2010; Weiss, 2006). The previous assumption that kink is inherently sexual has been challenged by various other studies, which have found that kink can in many cases be separate from sex (Connolly, 2006; Simula, 2019a; Sloan, 2015; Wismeijer et al., 2013;). Notably amongst these was a study conducted with asexual kink practitioners by Sloan (2015). The study found that for these participants kink was another way to gain trust or express intimacy (Sloan, 2015). The distinction for kink being sexual was the intent behind activities, namely if it was for the purpose of sexual desire or release (Sloan, 2015).

\section{Kink as serious leisure theory}

Newmahr postulated after her field work that kink was more akin to serious leisure than sex (2010). This framework was developed under a set of ethos that Newmahr took from Stebbins, an academic who has theorized serious leisure in opposition to casual leisure. The criteria for serious leisure are as follows:

1. the need for perseverance-in the face of resistance, participants return to their leisure pursuit 2. the leisure pursuit as a career

3. effort involving the acquisition of knowledge, training, experience and/or specialized skills 4. durable benefits - personal and social-psychological benefits of engaging in the leisure activity

5. unique ethos - the spirit of community

6. personal identification with the leisure activity (Newmahr, 2010).

This framework fits with the observations gained from both Newmahr's and Weiss's 
studies. Both studies were ethnographies of a kink community that took place mostly in public spaces. This meant that most interviews and observations occurred in the context of kink dungeons, clubs and conventions. In each study, the financial commitment needed to partake in kink was observed, as well as the acquisition of skills (Newmahr, 2010; Weiss, 2006). Under these stipulations kink was theorized by Newmahr (2010) to be a form of serious leisure in the context of her ethnographic study, as opposed to an inherent sexuality.

\section{b. Kink as a sexuality}

Some research has found that participants in kink state that kink is simply a part of who they are and possibly even an orientation. Various studies found that participants felt that kink was something they were born with and a strong part of who they are (Bezreh et al., 2012; Brame et al., 1993; Dancer et al., 2006; Meeker, 2013; Stiles \& Clark, 2008; Yost \& Hunter, 2012). The point of contention for many studies for considering kink a sexual orientation is whether or not participants consider kink to be sexual or count as sex. The Merriam Webster definition of sex is either: sexually motivated behaviour or phenomena, or sexual intercourse. Within heteronormative contexts, sex is almost always referring to sexual intercourse. For many of these studies, kink was described as something that could be complementary to sex, but was not synonymous with sex (Hebert \& Weaver, 2014; Newmahr, 2010; Simula, 2019a \& b; Sloan, 2015; Wismeijer et al., 2013). These studies found that kink could be a part of sexual expression but often was thought to be a sensory experience that may or may not involve sexual activity (Dancer et al., 2006; Newmahr, 2010; Simula, 2019; Sloan, 2015). In the case of Simula's (2012) study on bisexuality and kink, she found that participants would distinguish between sex and sexual, stating that there is a sexual energy exchanged but nothing that could be traditionally 
defined as sex. In another study, the difference between sexual and non-sexual kink was defined as the intentions for participating in kink (Sloan, 2015).

In Newmahr's ethnographic study on a kink scene in upstate New York, she made the argument that kink was separate from sex:

Kissing during play was rare, and genital play was much less common than other kinds of play (such as back-flogging). Participants often played with people they did not find sexually attractive and with whom they were not interested in being sexual. After play, participants normally went out to eat or home to sleep (2010).

There almost appears to be a distancing from sex and sexuality, and throughout Newmahr's work in this community, she describes it as something that is actually not related to sex at all and something entirely different. This is echoed in other studies which stated that participants did not consider their kink activities to be a preclude or replacement to sexual activity and that only $11.2 \%$ of participants exclusively engage in kink play during sexual intimacy (Hebert \& Weaver, 2014; Newmahr, 2010).

By contrast, another study of 24/7 slave relationships found that all participants engaged in sexual activity with their masters or mistresses (Dancer et al., 2006). A survey from the National Coalition for Sexual Freedom found that two thirds of their respondents said that they participated in kink for sexual purposes; however, only one third exclusively participated in kink with romantic partners (Gemberling et al., 2015). Therefore, whether kink is considered sexual appears to vary greatly depending on circumstances and personal opinions on both kink and sex.

\section{Kink and Sexual Orientation}

How kink interacts with sexual orientation provides some insight into a practitioner's relationship with their sexual orientation and with how to participate in kink. In a study conducted on asexual kink practitioners, sex was defined as 'just another kink' in relation to kink 
play (Sloan, 2015). For these practitioners, the fulfillment from kink came from intimacy, developing trust and self-discipline (Sloan, 2015). Various other studies have found that practitioners will often partake in kink with partners to whom they are not sexually attracted or do not match their sexual orientation (Bauer, 2008; Dancer et al., 2006; Newmahr, 2010; Simula, 2012). In these cases, most participants cited that kink compatibility was more important than any other factor, including gender (Bauer, 2008; Simula, 2012).

In Simula's (2012) study on bisexuality and kink, participants would differentiate between 'sex' and 'sexual,' saying that kink counted as sexual, but not sex, therefore the rules of their own sexual orientation and who they were attracted to sexually and romantically did not map onto their kink.

In these studies, is it apparent that the definition of sex and sexual varies greatly depending on the person and context. What is clear is that kink is important enough that, in some cases, it blurs the lines between other sexual preferences, such as the gender of a partner or even an interest in sex, as is the case with asexual participants. These studies show that kink supersedes other criteria for finding partners and, in some instances, is a separate criterion altogether from the criteria for choosing a romantic or sexual partner.

\section{c. Limitations and Missing groups}

In general, ethnographic studies have theorized that kink practitioners are typically well educated, white and often middle to upper middle class (Bauer, 2008; Gemberling et al., 2015; Newmahr, 2010; Simula, 2019a; Tripodi, 2017; Weiss, 2006). Many of these studies took place in public settings, such as kink clubs, dungeons or other kink events (Bauer, 2008; Newmahr, 2010; Weiss, 2006). As a result, there are research gaps regarding those who do not attend kink 
clubs or are not a part of a kink community. The studies that did not recruit participants through these spaces would often recruit through internet forums and focus on quantitative methods of data collection (Facio et al., 2015; Pascoal et al., 2015; Ritchers et al., 2008; Wismeijer et al., 2013; Yost \& Hunter, 2012). As Yost and Hunter (2012) mention in their own study, this likely leaves out practitioners who have no ties to a kink community or club. Additionally, the reliance on internet forums places emphasis on those who have internet access. In a study regarding sexual functioning and distress experienced by BDSM practitioners, the authors noted that because their study was conducted using the internet, their sample is likely to consist of a higher percentage of well-educated individuals who have access to the internet (Pascoal et al., 2015).

As a result of financial barriers, most who inhabit public kink spaces will usually come from higher economic classes, especially if they are regular attendees to these types of events (Bauer, 2008; Newmahr, 2010; Weiss, 2011). Due to many systemic barriers including money, many marginalized groups simply cannot access these spaces, or do not feel welcome or safe when the majority of attendees are white and middle class (Bauer, 2008; Simula, 2019b). This has resulted in most data regarding kink practitioners lacking racial diversity (Bauer, 2008; Newmahr, 2010; Simula, 2019b; Weiss, 2006). Additionally, other marginalized groups, such as those living with disabilities, trans individuals and lower income brackets, are missing from most kink studies (Simula, 2019b).

There are some studies regarding the lived experiences of kink practitioners outside of public spaces and/or psychological contexts, such as Sloan's (2015) study of asexual practitioners and Dancer et al's (2006) study of 24/7 slave relationships, but there is still a lack of research on lived experiences of kink practitioners, as mentioned by Dymock (2012) and Simula (2019a). 


\section{Sexual Orientation}

\section{a. Historical Understanding}

The word homosexual was first added to the English language in 1892 when Charles Chaddock was translating a medical handbook on sexual deviances from Krafft-Ebing (Martinson, 1994). Prior to this, there were no words or identities established to describe sexual interest in any gender (Martinson, 1994). In ancient societies, such as Greece and Rome, the focus was on sexual behaviour and not on the identity of one's sexual partners (Martinson, 1994). It was common in ancient Greece for men to have sexual intercourse with young boys; this was viewed as simply a common sexual activity and not as an expression of an inner identity (Martinson, 1994). The societal shift in the $19^{\text {th }}$ century from focusing on the act of sex to focusing on sexuality "as a psychological and physiological reality constituting something essential to the self" (Martinson, 1994) is what lead to the words homosexual and, eventually, heterosexual entering the English language and becoming distinct categories.

In these early contexts, homosexuality was defined by Krafft-Ebing as "the demonstration of perverse feelings for the same sex; not the proof of sexual acts with the same sex. These two phenomena must not be confounded with each other" (in Sell, 1997). The definition of homosexuality, which predated heterosexuality entering the English language, focused on homosexuality as a sexual deviance and something that needed to be cured (Sell, 1997). These early definitions exclude sexual behaviour and place the emphasis on the mere desire or thought of homosexuality as the defining factor (Sell, 1997).

There was a shift when Alfred Kinsey and his colleagues began their research into sexual orientation and eventually developed the Kinsey scale. The definition of sexual orientation was 
then broadened to include people who are attracted to the opposite gender, the same gender or both (Tweedy, 2011). The Kinsey scale stated that everyone was on a scale ranging from exclusively homosexual to exclusively heterosexual, with the middle representing bisexuality (Kinsey et al., 1948). Kinsey stated that he wanted to create a scale because within the world rarely are things divided into two distinct and separate categories (Kinsey et al., 1948). Despite this claim, this framework categorizes people into clear binaries of gender, excluding those who do not fit within those binaries (Klesse, 2014).

The issue with these early definitions of sexual orientation is that they place homosexuality and heterosexuality in opposition to each other. The Kinsey scale, while allowing for some fluidity, still places homosexuality and heterosexuality at opposite ends, further creating an either/or (Sell, 1997). Additionally, these early definitions mostly relate homosexuality to deviant desires and lack focus on actual behaviour. Homosexuality is, therefore, defined as something that needs to be corrected and is akin to a psychological disorder, much in the same way kink was later defined.

\section{b. Current Understanding}

Current understandings of sexual orientation are defined in two ways: sexual orientation as a psychological state or sexual orientation as a behavioural activity (Sell, 1997).

As the title of this thesis suggests, there is a common belief regarding sexual orientation that people are 'born that way.' The benefits of this framing of sexual orientation for LGBTQ+ communities is to put to rest the idea that people can be 'made' gay through their environment or can choose to not be gay. Some studies have subsequently tried to locate a 'gay' gene or other biological factors that determine sexual orientation (Klesse, 2014). The idea that sexual orientation is ingrained helps to delegitimize harmful practices, such as conversion therapy, and 
advocates for people to accept queer identity as a natural part of human experience. In relation to kink, this argument has also been used to lessen discrimination (Dancer et al., 2006; Gemberling et al., 2015; Moser, 2016; Stiles \& Clark, 2008).

Previous studies have tried to prove the immutability of sexual orientation, mostly for the purpose of legal cases and fighting discrimination. In one study of identical twins who were raised separately, it was found that when one twin was gay, there was a $52 \%$ increase in likelihood that the other twin was also gay (Martinson, 1994). This was in comparison to fraternal twins where the correlation was only 22\% (Martinson, 1994). This discovery lead to concerns that the discovery of a supposed gay gene could theoretically feed into anti-gay eugenics (Halley, 1993-94). Therefore, this could fuel research and discourse on how to 'cure' this genetic mutation and further current homophobic rhetoric that homosexuality is a genetic mutation that needs to be stopped (Halley, 1993-94). Halley also mentions in her article that there is still a lack of evidence that sexual orientation is immutable. Additionally, she mentions that this fails to take into account the social, political and fluid aspects of sexual orientation (1993-94).

In terms of sexual orientation, there can be social factors, in addition to biological ones, that can determine how someone chooses to identify. These reasons could include the desire for a relationship that is free of stigma or provides financial stability (Wilton, 2004). For her book, Wilton interviewed hundreds of women ranging in age from early 20 s to middle age, asking about their experiences with sexual orientation and attraction. Of the women interviewed for this study, there were many common themes throughout regarding the expectation of heterosexuality and the fear of deviating from it. Participants mentioned that they saw heterosexuality as the only 
option and that having a serious relationship with a woman often meant there was "traumatic other stuff that goes with it" (Wilton, 2004).

Lisa Diamond's book Sexual Fluidity examined sexual orientation in relation to women and how it can change over time. Diamond conducted interviews with women over the course of ten years regarding their sexual orientation and how they experienced attraction (Diamond, 2008). In these interviews, some women mentioned their attractions changing over the course of ten years. In some cases, this would mean that a woman who previously identified as straight would identify as a lesbian at some point within ten years (Diamond, 2008). One of Diamond's interview subjects named Karen changed how she identified considerably over the ten-year period that Diamond interviewed her. In the beginning, Karen strictly identified as a lesbian, having previously mostly identified as straight (Diamond, 2008). When Karen was interviewed a third time, six years after the first interview, she was in a relationship with a man and stated that her attraction to women was still stronger, but, upon further reflection, realized that she still felt attraction to men; she just experienced it differently than her attraction to women (Diamond, 2008). A recent study done by Diamond on men and women of various sexual orientations found that $82 \%$ of lesbian/bisexual women and $78 \%$ of gay/bisexual men reported changing their sexual identity label at least once since adopting a non-heterosexual identity (Diamond et al., 2016). Both this study and Katz-Wise's in 2015 concluded that, overall, women did not in fact have higher sexual fluidity than men, but that there are various other social factors and timelines that can contribute to overall sexual fluidity.

Therefore, if the framework that sexual orientation is something people have to be born with is not applicable to being gay or straight, then it could also be applied to kink. Most literature argues that an interest in kink typically becomes apparent with either puberty or the 
start of sexual activity (Bezreh et al., 2012; Pascoal et al., 2015; Stiles \& Clark, 2008; Yost \& Hunter, 2012). However, one study found that there was an average of six years between discovering interest in kink and first experience with kink, showing that there is a delay in acting on these desires (Gemberling et al., 2015; Pascoal et al., 2015). Part of the reason for this delay was due to fear of discrimination and stigma surrounding kink practices (Bezreh et al., 2012; Gemberling et al., 2015; Pascoal et al., 2015). Diamond mentions that culture and environment are important factors when it comes to sexual attraction and, by extension, expression of that attraction.

Wilton's study paired with Diamond's showcase the fluidity and complexity of female sexuality. From these studies it can be concluded that there are many societal and social factors that impact sexual orientation.

Therefore, conceptualizing sexual orientation in terms of what it means not only biologically, but also socially and politically, makes logical sense. In particular, theorists have deconstructed how sexual orientation is defined and argue that present definitions are limiting and often contradictory between the concepts of immutability and fluidity (Ahmed, 2006; Butler, 1993; Diamond, 2008; Hubbard \& Wald, 1994; Tweedy, 2012). Studies on marginalized sexualities, such as polyamory or kink, have reasoned that the category of sexual orientation is crucial in fighting against discrimination of these identities (Gemberling et al., 2015; Moser \& Kleinplatz, 2006; Wright, 2010). Additionally, various studies have made the argument both from a legal and social standpoint that polyamory should also be considered a sexual orientation (Klesse, 2014; Tweedy, 2012; Vrangalova \& Williams, 2012). In relation to these studies, various scholars have then sought to re-define sexual orientation, as the present definition was too narrow and did not reflect their relationships or activities of poly- and kink-identified 
participants (Gemberling et al., 2015; Klesse, 2014; Moser, 2016; Simula, 2012; Tweedy, 2012; Vrangalova \& Williams, 2012).

A later study conducted in 2015 found that there was a greater instance of reported sexual fluidity amongst its participants, citing the cohort effect as a possible reason (Katz-Wise, 2015). Katz-Wise mentions that due to greater advances socially regarding sexuality and sexual orientation, with more acceptance towards non-heteronormative sexualities, it makes sense that young adults in 2015 report more instances of sexual fluidity than they did in 1998 when Diamond was conducting her earlier study (2015).

The responses from women who identified as heterosexual were surprising in how similar they were to women who identified as queer or lesbian. The heterosexual women said that they had strong physical and emotional intimacy with female close friends and, in some cases, sexual intimacy, however they still identified as heterosexual (Wilton, 2004). One participant in Wilton's study mentions that she saw heterosexuality as her only option and would then channel her high sex drive into the only thing she knew she could (2004). Wilton does mention that there is a very apparent generational gap with her participants. Those who are a part of older generations cited seeing heterosexuality as the only option and, therefore, lived accordingly to fit within that construct, whereas participants of younger generations were more able to express other orientations with less fear of stigma and retribution (Wilton, 2004).

All of these social constructs have profound effects on how people identify, and even define, sexual orientation. Many participants mention a sense of duty and 'have to' with relation to dating and marrying men (Diamond et al., 2016 \& 2008; Wilton 2004). Some even express disgust when the subject of sex with men is brought up, showing no signs of attraction and 
almost a civic duty towards having sexual relations with men. Some of these women even claim that they wished they could be lesbian but simply could not be.

In relation to kink, this could explain why some only discover kink later in life. If kink is stigmatized, deviantized or even potentially criminalized, one can hypothesize that fewer people would want to be associated with kink.

Putting all these theories together, it can be surmised that sexuality, and specifically sexual orientation, can be shaped by many external and internal factors. Fear of stigma and overall ease of relationship were cited as key factors that can deter the women in Wilton's study from pursuing non-heteronormative relationships (2004). This is also true with relation to kink (Bezreh et al., 2012; Gemberling et al., 2015; Pascoal et al., 2015).

\section{c. Theories that expand scope}

Sarah Ahmed (2006) postulates that orientation allows for us to take up space and time; she describes it more as a journey than a destination and something that is not just about the present but where we are going in the future. Recent studies have begun to make the argument to expand the scope of sexual orientation to include other identities, such as kink and polyamory (Klesse, 2014; Gemberling et al., 2015; Tweedy, 2012; Vrangalova \& Williams, 2012). Specifically, there is growing research to suggest that kink should be considered a sexual orientation, or at least a core part of one's identity (Dancer et al., 2006; Gemberling et al., 2015; Moser, 2016; Stiles \& Clark, 2008; Yost \& Hunter, 2012). Various studies have found that participants will state that kink is a crucial part of their identity (Bezreh et al., 2012; Brame et al., 1993; Dancer et al., 2006; Stiles \& Clark, 2011; Yost \& Hunter, 2012). As a result of these studies, some scholars have begun to theorize that sexual orientation should include our sexual 
interests, behaviours, desires and how we choose to identify (Diamond, 2008; Klesse, 2014;

Miletski, 2017; Moser, 2016). These definitions of sexual orientation focus on the nebulous and ever-changing aspects of sexual orientation, rather than just the gender one is attracted to.

Diamond's book Sexual Fluidity (2008) explores the concept of sexual fluidity, with a focus on the experience of desire and attraction in women. In particular, Diamond notes that many researchers do not define, nor seem to greatly understand, how individuals experience sexual attraction. She points out that we do not ask what each person means when they say the word attraction or even what it feels like.

Studies and research on sex in general assume heterosexuality unless stated otherwise (Wilton, 2004). Therefore, heterosexual sex is synonymous with 'normal' sex in most contexts. The result is that in order for homosexuality to be studied, it is often compared to heterosexuality (Wilton, 2004). Additionally, sexual attraction was more than just the gender of the person in question but, in some cases, was the activity that was going to take place.

Even the word "attraction" can have different connotations. When Diamond asked her participants to define and describe what attraction felt like to them, she received a wide array of answers (2008). She noted that there was a difference between women who had consistent attractions to both sexes and those who had bisexual potential that could be triggered by the right person or opportunity, which would otherwise lie dormant (Diamond, 2008). Therefore, it is reductive to frame sexual orientation as something that is essentially biological and remains static throughout life. Further, it could be used as a framework to explain whether or not kink is a sexual orientation.

However, broadly speaking outside of academic circles, sexual orientation is still often thought of as meaning the gender to whom one is attracted or with whom one has sex 
(Tweedy, 2011). In most cases, this means whether a person is attracted to the same sex, the opposite sex or both, limiting sexual orientation to three distinct categories (Tweedy, 2011). Anne Tweedy notes that the prevailing definition often takes for granted the actual definition of both the words "sexual" and "orientation" placed together. She writes that neither the word "sexual" nor the word "orientation" reference the sex of the person to whom one is attracted (Tweedy, 2011). She writes further that this fails to account for the fact that many people are more drawn to or oriented towards certain body types, hair colours and other physical attributes (Tweedy, 2011). In other studies, it was found that some kink practitioners value kink compatibility over the gender of their partners (Bauer, 2008; Dancer et al., 2006; Simula, 2012).

Tweedy (2011) mentions the paradox of considering orientation both fluid and essentialist, as both concepts are not compatible with the other. According to theorist Judith Butler (1993), the definitions of both heterosexuality and homosexuality are dependent on each other to gain meaning through opposition. Therefore, homosexuality is constructed as the opposite of heterosexuality, and without heterosexuality, homosexuality could not be so easily defined (Butler, 1993). Considering sexual orientation from an essentialist vantage point denotes that it is a trait that is necessary to identity and often unchanging (Cartwright, 1968). This suggests a fixed trait, rather than a fluid and ever-changing trait as mentioned by Butler (1993), Diamond (2008) and Wilton (2004). Therefore, considering sexual orientation as something that is essentialist and therefore permanent is at odds with the emerging theories that sexual orientation is fluid.

Another article on the prevalence of bisexuality within the kink community noted that other factors outside of the gender of choice influence sexual identity; therefore, sexualities that do not fit within this framework such as polyamory, fetishism and sadomasochism are not 
considered a part of sexual orientation, yet they are often considered a part of sexual identity (Simula, 2017). Put simply, these articles suggest that defining sexual orientation as attraction to a particular gender is reductive. Additionally, the concept of sexual identity and orientation should be more closely tied together in terms of definitions, as both draw on similar aspects of sexuality.

\section{d. Legal Issues}

Researchers have found that kink's acceptability often hinges on its proximity to sexual normative practices, such as heterosexuality, monogamy, and long-term or marital couplehood (Dymock, 2012; Stiles \& Clark, 2011; Tripodi,2017; Weiss, 2006). This is a form of respectability politics, which is defined as a set of beliefs stating that a marginalized or minority group needs to adhere to a set of values and appearances determined by mainstream standards in order to minimize their oppression (Smith, 2014). Within the context of kink, this is apparent in the treatment of kink within LGBTQ+ spaces.

In her work on legal cases and case law, Khan (2014) found that even at the judicial level, judges are more lenient with cases of sadomasochism if they are within the context of a heterosexual marriage. A similar comparison can be made between polyamory and the LGBTQ+ community. Tweedy mentions that within the lesbian feminist community there was significant backlash against the polyamory movement, which was perceived to contaminate the 'pure' nature of lesbian feminism (2011).

Under Canadian Law, any contact that results in bodily harm in the form of bruises or marks may constitute assault (Luksic, 2015). There are exceptions to this law, for example in relation to sports or medical procedures. However, when it comes to sex, this law is often 
enforced, meaning that if injury occurs in the course of consensual BDSM activity, one partner could be charged with assault. Researchers in sexuality have called this phenomenon sexual exceptionalism. What this means is that sexual risks and injuries are perceived as more harmful than non-sexual risks and injuries (Khan, 2015).

In the case of consent to harm laws, sports activities are given the exception, whereas kink, because of its association with sex, is not; both acts are consensual, but one is demonized. This exception is telling because in the case of sports like boxing, football and hockey, the injuries sustained are often more severe and can have lasting damage (Dekosky et al., 2010; Gulli, 2011; Morgan. J, 2018;). The average flogging or spanking, might leave bruises (Luksic, 2015).

Under current legal frameworks, there is one case that suggests that kink discrimination may be grounds for legal action. In 2005, Vancouver resident Peter Hayes was denied a chauffeur permit to work for a limousine company, in part, because of his involvement in BDSM (Hainsworth, 2008). When Hayes pressed further for details, the investigating officer told him that his kink-related identity and practice (which were framed as "pagan cult" involvement) made him a "danger to society" (Hainsworth, 2008). Throughout the case, fear mongering and a lack of understanding were evident. Ultimately, the case was dismissed on evidentiary grounds, but the Court left open the question of whether kink should be classified as a sexual orientation for the purposes of provincial human rights legislation. The case thus indicates that if kink were to be widely accepted as a sexual orientation, then kinky individuals would be able to access protection from discrimination through provincial and federal Human Rights legislation, as well 
as through the Canadian Constitution, particularly with regard to the equality rights guaranteed under section 15 of the Charter of Rights and Freedoms. ${ }^{1}$

Law professor Brenda Cossman is vocal about the need to loosen the grasp criminal law has on sex and, specifically, sexual harm (Cossman, 2020). Cossman is a staunch advocate for using restorative justice and other resources to address and deal with sexual harms, as she mentions that the framework given by criminal law is simply not suited to dealing with the complexities of human sexuality (Cossman, 2020). Because of consent to harm laws and because BDSM is still in the DSM, this means that regulation of kink is in the hands of both the legal system and the medical system. When it comes to kink, the institutions of power are labelling these consensual behaviours as either deviant or criminal and, in some cases, both. Cossman mentions that if we make something a crime then we give the power to the state, which then gives the state the power to define it (Cossman, 2020). In the case of BDSM, the state can define it as assault and therefore punishable by law, or a disorder, which needs to be diagnosed and treated. Given the predominance of these frameworks, it is not a surprise that BDSM practitioners still face stigma.

Cossman says there are two sides to the arguments regarding justice for sexual harm: one side that claims there is a lot of sexual injury that has not been addressed and needs to be, and another side that says that criminal law is being overused for these purposes (Cossman, 2020). Within the context of criminal law, sexual harm can only be determined through due process, meaning that something has to be proven to be harmful when compared to set definitions given by the state as to what is considered harmful (Cossman, 2020). The issue with this framework,

\footnotetext{
${ }^{1}$ Canadian Charter of Rights and Freedoms, s 7, Part 1 of the Constitution Act, 1982, being Schedule B to the Canada Act 1982 (UK), 1982, c 11.
} 
especially as it relates to sex and to kink, is that what one person considers harmful, another will consider pleasurable. Setting a standard definition of what constitutes sexual harm has been up for debate for decades with regard to what is considered rape, and even the legal reframing from rape to the broader term of sexual assault, which considers more than just penetration. Therefore, as Cossman says, criminal law, by its very nature, is an inefficient tool for deciding what sexual behaviour is legal and what is criminal.

Ultimately, I argue that there is a failure to substantiate Pierre Trudeau's famous proclamation, "there is no place for the State in the bedrooms of the nation." ("Trudeau: 'There's No,"” 1967) . In that case, the former prime minister was referring to the decriminalization of homosexual acts through an Omnibus bill in 1967. He continued that "what's done in private between adults doesn't concern the Criminal Code" ("Trudeau: 'There's No," 1967). Over 50 years later, homosexuality is increasingly more acceptable in society; however, other aspects of sexuality are still under surveillance and subject to criminal law. Notably among these are sex work and BDSM. Thus, in practice, Canada is failing at staying out of the bedrooms of the nation, as some sexual activities are still in legal grey areas.

The literature presented here demonstrates the evolution of how kink has been studied from a psychological and sociological perspective. Existing research shows a similar trajectory to homosexuality, whereby it was first pathologized and gradually moved towards being considered a community and identity that was worthy of social acceptance and legal protection. The literature presented shows gaps with regards to lived experiences of kink practitioners and narrow demographics when conducting ethnographic research. Therefore, this thesis seeks to examine lived experiences of kink practitioners and their conceptualizations of sexual orientation as it relates to kink outside of established community forums or ethnographic groupings. The 
following chapter will detail the empirical component of this study that allowed me to gain insight into these questions. 


\section{Chapter 3: Methods}

In this chapter, I will review my research methods. For this project, I employed a single method approach of qualitative interviews. The following chapter will review how I recruited participants and the characteristics of my sample. Additionally, I will explain how data was coded to construct common themes. Finally, I will analyze the limitations and benefits of my methods.

\section{Recruitment of interviewees}

Once I received my approval from the Carleton University Ethics Board, I began to circulate my recruitment poster (see Appendix B). The poster was circulated on my own social media, as well as the social media of another researcher whose research interests are similar. The posts on social media were able to be shared and be seen by anyone, which expanded the reach of the posts. The same recruiting poster was used across these platforms to get participants (See Appendix B).

I sent in my materials for approval to be posted on FetLife, a social media site dedicated to kink practitioners. This required me to contact their web administration and send them a research proposal, recruiting materials and proof of ethics clearance (See Appendix F). I received approval from FetLife to post recruiting materials. However, I ended up not using them, as I was able to get enough participants for the scope of this thesis by other means.

Recruiting took place over the course of two months, after which time I felt I had the right number of participants for the study. Participants would contact me via email to express interest in the study. Once this was established, I would ask them a couple of general screening questions to get a better idea of their involvement with kink and why they were interested in participating in the study. I would also ask if they thought kink should be considered a sexual 
orientation to ensure they had thought of the main research question. If they were established to be a suitable interview candidate, then an interview was scheduled either in person or via Skype depending on the location of the participant.

In addition to these recruiting methods, snowball sampling was also used. Snowball sampling is when someone recommends or refers a participant to the researcher (Patton, 2015). A benefit of this recruiting method is that it can enable access to marginalized populations and/ or populations that are harder to reach through other means (Goodman, 1961). As mentioned, above, I sent my recruitment materials to a fellow graduate student who then circulated the poster on her social media channels. This resulted in three participants contacting me to schedule an interview. One of these participants shared the poster with a friend who then also contacted me by email to express interest in the study. Therefore, snowball sampling allowed for a greater reach for participants and helped to increase the number of participants for this study.

\section{Sample}

In order to participate, participants had to be at least 18 years of age, had to have been active in practising kink for at least six months, and be living in either the United States or Canada. For recruitment, I set a goal of five participants. I found that through circulating my materials and snowballing, I was able to get more participants than my goal. Recruitment yielded seven participants from both Canada and the United States. The main reason I included the extra two participants was in case one participant dropped out or failed to schedule an interview. Overall, I did not find that I had difficulty in recruiting participants. Part of this could be due to my positionality as an insider with personal connections. Three participants were recruited from a Twitter post of another colleague. One participant was recruited through snowballing, with the remaining three participants recruited by responding to recruitment material posted by the lead 
researcher. Of the participants, two identified as transgender and five were cisgender or did not specify. There was only one male identified participant in this study, and the remaining participants identified as female.

In general, the sample was mostly white or white passing. While I hoped I would get more of a racially diverse sample, I acknowledge that as a white woman there are barriers to me reaching those populations. For future research, this could be mitigated by recruiting in spaces that are specifically for kinky people of colour. This could include support groups, online forums and community spaces. Due to many kink spaces being predominantly white, recruiting in those spaces would yield the same results. Therefore, for future projects, it would be beneficial to do more research into what spaces racialized people occupy within kink and recruit in those spaces.

Most of my participants also identified as bisexual and/or queer, meaning they are still able to participate in the predominantly heterosexual kink scene. As Bauer mentions in their study of dyke and trans kink spaces, spaces that are exclusively queer are fewer in numbers and often harder to find (2008). Previous research has claimed that the average kink community in most cities is mostly white and mostly heterosexual; from my own experience, I can say that this does appear to be true (Bauer, 2008; Newmahr, 2010; Simula, 2019a; Tripodi, 2015; Weiss, 2006;).

Due to the smaller scale of this approach, quantitative data is lacking from this research project. Originally, I did want to have a survey portion to counter this; however, finding enough participants to have a good data set proved to be cumbersome for the timeline of this project. Due to the timeline for completion, I opted to not do the survey portion, as I thought that for this project the qualitative portion was more integral to the dissertation. However, this means that the 
data set could lack more diversity as a result of this and that there is less data regarding the research question of whether or not kink should be considered a sexual orientation.

\section{Data Collection}

\section{a. Interview Procedure}

Seven participants from both Canada and the United States were interviewed for this project. Participants were briefed with an informed consent form (see Appendix D) at the beginning of the interview, which outlined the purpose of the study and ethical considerations. At this stage, participants were given the opportunity to ask questions or express any concerns about the study. In-person interviews were conducted in public spaces, such as cafés or rooms at Carleton University. Participants were asked if they had a preference for location. This was done to be considerate of the private nature of what participants would be sharing in interviews.

Interviews that could not take place in person were conducted over Skype. This was three of the seven interviews. For these interviews, participants were read an oral consent form, rather than given a form to sign (see Appendix E). A copy of the form was then sent to the participants so they could have the contact information of the Carleton Ethics Board if need be.

Interviews lasted between 25 and 60 minutes. The interviews were semi-structured with a list of guiding questions, but sometimes I would use probing questions when interesting points were brought up (See Appendix C). All interviews began with a general outline of the research question of whether or not kink should be considered a sexual orientation. The first question asked in interviews was what the participant's kink origin story was. I found that this question was a productive way to ease into the interview, as it would often naturally lead into the other 
questions. While I had a general order for the questions, I would not often ask them in a specific order. The order of questions was determined based on how the conversation naturally developed. Questions were merely there as a guideline. All questions on the question guide were asked in each interview. During the interviews, I took notes, in addition to audio recording the interview. At the end of the interview, I thanked the participant and asked if there was anything else they wanted to add or discuss.

\section{b. Semi-Structured Interviews}

The interviews for this study were semi-structured and took place between February 2019 and April 2019. Semi-structured interviews were deemed the best method to gain insight into the lived experiences of participants, as was the goal of this study. Semi-structured interviews provide participants with flexibility to answer questions and guide the interview toward what they feel is most important (Hill et al., 1997; Knox \& Burkard, 2009). Through this method, participants were able to bring up unanticipated information that could be of use for my study (Arksey \& Knight, 1999; Seidman, 1991). Due to the varying definitions of kink and sexual orientation, I felt that this approach would work best and give participants the freedom to express their experiences and opinions.

Questions in the interview addressed the participant's definition of kink, definition of sexual orientation and whether or not they thought that kink should be considered a sexual orientation. Background regarding the participant's involvement and interest in kink was asked first to get a better idea of how long the participant had been involved and when they noticed their interest in kink. I then asked a series of questions about their definition of kink, sex and sexual orientation. I then posed the question of whether or not they think kink should be 
considered a sexual orientation, followed by questions related to the perceived benefits or detriments of defining kink as a sexual orientation.

Overall, I found the focus on interviews to yield more nuanced and detailed responses than if I were to only focus on surveys or other quantitative methods. The one area that quantitative methods could have proven useful is to answer what percentage of kink practitioners do think that kink should be considered a sexual orientation. Additionally, quantitative methods could have more broadly answered the type of benefits and detriments experienced or perceived from considering kink a sexual orientation. However, for the purpose of this dissertation, I thought that more detailed responses would prove more useful than survey responses, as more nuance and context can be explored through interviews. Further, the main constraint for this project was time. In order to dedicate enough time to recruit, interview, transcribe and code, I had to take this into account when deciding whether or not to do a survey as well. In the end, I decided to focus on the interviews and not do surveys, as I felt that this would prove more useful for my research questions.

\section{Data Analysis}

\section{a. Primary Coding}

Once interviews were complete, I transcribed the interviews in full. Transcriptions included all pauses, emphases and laughter that happened in the interview. This was done to gain insight and nuance into the meaning behind participant answers. Transcriptions were done wordfor-word to avoid misinterpretations during analysis (Bryman, 2012). Once this was finished the transcriptions were coded using NVivo software. During coding, I was looking for common themes in terms of definitions and potential benefits of considering kink a sexual orientation. I 
also looked for discrepancies in answers between the questions regarding if participants thought kink should be a sexual orientation and if it was the core part of who the participant was. I looked for differences in answers depending on when they became involved in kink, what type of kink and social location. Passages were coded using nodes, which were phrases that stated the main topic of what was being said in the passage (van der Helm, 2016). This allows for a wide range of answers and/or insight into similar topics (Braun \& Clark, 2006). When this was complete, I coded the existing literature on the subject under the same nodes in NVivo surrounding the definition of sexual orientation, benefits, detriments and other studies done. This was to provide a comparison between existing literature and my current project. Through this I was able to see discrepancies and similarities between my study and other studies. Additionally, this provided insight into areas of research that need to be explored more.

\section{b. Secondary analysis}

Once primary coding was complete, I began to further analyze the data in comparison to existing research. I used grounded theory in analyzing my research, as grounded theory focuses more on finding trends and framework within the data itself, instead of applying an existing framework to the data (Charamaz, 2006; Faccio et al., 2014). Grounded theory involves continuously analyzing data sets throughout the research process (Charmaz, 2006). This means that theories and frameworks emerge from the data itself and are not applied to the data (Charmaz, 2006). Therefore, this involves constructing theories from past and present interactions with other theories and lived experiences, rather than discovering them (Charmaz, 2006). In short, this means going into interviews without preconceived notions about what the answers will be and building framework and theories from what participants say. 
I felt that this approach made the most sense for the purpose of my research, as there is insufficient research on the lived experiences of kink practitioners (Dymock, 2012).

Whereas primary coding focuses mostly on sorting the data into categories, during secondary analysis, I focused on narrowing the data to content that related to my research questions. Tangents or passages that did not answer my main research questions were set aside for potential use in future projects. The emerging themes were then organized in essay format for an outline of potential chapters for this dissertation.

Direct quotations were edited to remove filler words, "ums" and repetitive words. This was done for the purpose of clarity and to ensure that quotes were easy to read.

\section{Ethical Considerations}

\section{a. Insider/Outsider}

Within the academic community, there is a debate regarding whether or not it is better to be a part of the group you are researching or to be separate from it. There is a common idea that if someone is an insider, they will have more authority over the group that they are researching (Bridges, 2001). However, this idea is merely a perception and, consequently, their viewpoint will be multi-layered and sometimes inconsistent, negating their authority (Bridges, 2001). While being considered an outsider can have its advantages with regards to objectivity, it can also have its complications with regards to access. Being an insider can allow for greater access to certain populations, especially if they are marginalized (Sherif, 2001). However, this can have other complications where your research subjects view you more as a friend than a researcher (Sherif, 2001). 
With my research, I see this as being a particular challenge to obtain a balance between objectivity and relating to the subjects. In my experience through journalism, it is often very easy when you can relate to the interview subject to make the interview more conversational, in order to put them at ease. While I think this can be valuable, it is still important to keep the line between researcher and subject clear.

I would position myself as an insider because I have taken part in kink play. I know firsthand that the experience allows for fluidity not present in traditional sexual experiences and that playing with power dynamics is both appealing and very fun. Through these experiences, I am aware of the many protocols and terminology used in these circumstances. Additionally, I have firsthand experience with some of the sensations and feelings at play when partaking in these activities. I did find this firsthand knowledge to be useful when I was conducting interviews. It enabled me to already know certain terms and jargon such that when it came to probing for answers, I felt that I was able to ask better questions as a result. For the purposes of my research, I felt that it was important to disclose some of this to my participants, as I was asking them to trust me with very personal details. I also think that this knowledge gives better understanding to what positionality I am coming from and how it shapes my research.

When I was conducting interviews, I decided to disclose my involvement within kink if it came up naturally in conversation or as a means to relate to points my participants were bringing up. In general, I found this to be a useful tool to establish rapport with my participants and often would result in greater detail about their experiences. In some instances, I did not feel it was necessary, as my participants were already at ease with discussing this topic. I found that in both in-person interviews and Skype interviews, it was easy to establish rapport and comfort levels with my participants. If I mentioned my involvement and personal interest in kink, I tried not to 
take control of the conversation and was mindful of how my answers might shape what my participants were willing to say.

Another reason to disclose my insider status would be to mitigate some of the perceived power dynamics between myself as the researcher and the participants (Craene, 2017). However, there is a common fear among researchers that they will lose scientific credibility if they do disclose their sexual interests in relation to their research (Craene, 2017). I would argue that rather than taking away from my research, it adds to it, as I have a better understanding of the lived experiences of my participants.

\section{b. Psychological Stress}

Given the potential social risks that may result from kink practitioners participating in my study and the sensitive nature of the information disclosed, I took precautions to ensure the wellbeing of participants. Before interviews, I read an oral consent script or gave participants an informed consent sheet if interviews were done in person (see Appendix D \& E). Both the consent form and script included an overview of the study with potential risks and benefits of participating in the study. Participants were told they could email the lead researcher up to one month after the interview if they wanted to remove any details or withdraw from the study. If they chose to withdraw, all data relating to their participation would be destroyed. If participants wished to terminate the interview, they had the right to do so, withdrawing any data collected as well. Participants were also informed that they did not have to answer all questions and could refuse questions they were not comfortable with. On the consent forms, I outlined potential resources for support in case they experienced any psychological stress as a result of this interview. These resources included mental health supports and community supports related to kink. 


\section{c. Confidentiality}

Due to the sensitive nature of kink and how kink practitioners can be vulnerable to stigma, various measures were taken to ensure the privacy and confidentiality of participants. Participants were asked in the informed consent form if they were fine with being audio recorded. All participants agreed. The audio recording was used for transcription purposes only. Once transcription was complete, the recording was destroyed. Each participant was given a pseudonym, and their transcripts were labelled using a code name. Interview transcripts were altered to remove any identifying characteristics (name, place of work, location). Transcripts and audio recordings were encrypted and kept on a password-protected computer, and access was restricted to myself and my supervisor.

Overall, I felt that qualitative interviews resulted in a good data set for the purpose of my research questions. This method yielded nuanced and sometimes unexpected responses that allowed me to gain more insight into the question of kink being a sexual orientation. The following chapter will analyze participants responses. 


\section{Chapter 4: Results}

This dissertation considers the implications and suitability of framing kink as a sexual orientation. In order to research this question, participants who self-identified as kinky were recruited and interviewed regarding their perspectives on the relationship between their kink subjectivity and the concept of sexual orientation. This chapter will detail the results of those interviews.

The first section will cover the main research question of whether or not participants thought that kink should be a sexual orientation. First, participant definitions of both sex and sexual orientation will be discussed, followed by the kink origin story of participants and trends in that data. The next section will focus on the consensus that considering kink a sexual orientation would be beneficial from a legal standpoint.

\section{Is kink a Sexual Orientation?}

\section{a. Born this way/Immutability}

Broadly speaking, sexual orientation is generally defined as the gender to which someone is attracted, both romantically and sexually (Kinsey et al., 1948; Shively et al., 1984; Vrangalova \& Savin- Williams, 2012). Sexual orientation has been theorized to be an inborn characteristic (Halley, 1993-94; Kinsey et al., 1948; Vrangalova \& Savin-Williams, 2012). Recently, scholars have argued that while sexual orientation can be inborn, it is also capable of changing and evolving over the course of a lifetime (Diamond, 2008; Halley, 1993-94; Katz-Wise, 2015; Wilton, 2004).

Participants in my study had difficulty coming up with a concise definition of sexual orientation. Most stated that sexual orientation was who you want to engage in sexual activity 
with, but some felt that that definition did not fit with their lived experience. This was mostly because what constituted sexual activity varied from participant to participant, as is shown by the quotations below. Jessica defines sex as:

It doesn't have to be penetration, it doesn't have to be any of the sort of obvious definitions of sex. It just has to be two people or more seeking some sort of sexual pleasure with each other, doesn't have to end in orgasm, it can, doesn't have to involve genitals, it can.

Whereas Grace defines sex as "just two people using their bodies and imaginations to make each other feel pleasure." Nicole defined sex in terms of physicality: "I think sex, for me, it's a level of physical and emotional intimacy. It definitely is based in physicality for me." Therefore, all definitions of sex generally surrounded pleasure and expressing physical intimacy with desired partners. The specific activities this entailed differed from participant to participant. By extension, orientation was defined as with whom they wanted to partake in these activities. Two participants defined it as what guides them to be sexually fulfilled, including activities, desires and people that will fulfill these desires. Marcie explains:

I guess it's how I find my sexual pleasure, like how I find my sexual pleasure. My sexual orientation is the script that exists within my brain that allows me to feel sexually fulfilled.

Lily said that the general definition of sexual orientation does not apply to her, as her sexual desires are more geared towards things happening or certain experiences, rather than a specific gender. Lily identifies as a trans queer woman. In addition to this, she mentioned that when it comes to sex, she no longer engages in what is known as 'vanilla' sex or, put simply, sex that is normative and not kinky. For these reasons, she felt that the classic definition of sexual orientation that centred on the gender of one's potential sexual partner did not really apply to her: In a broad sense to the larger definition of sexual orientation is what genders of people do you have sex with, and that isn't a very significant aspect of my desires. 
She mentions that because she is queer and kinky, her experience of sexuality in general is outside of what is traditionally considered sex or sexual. Rather than focusing on the gender of her partners, she is more focused on the activities they will do together and if they are interested in the same types of BDSM, which for her involves rope bondage and dominance and submission. She explains:

There are specific things that I like happening. I like rope bondage, that's a good example, that is a thing that I like. I don't really care who's doing it, I care if they're nice, I care if they are good looking to me, but beyond that like I don't really care if it's a man or a woman or someone who isn't either.

This experience was similar to three other participants, for whom their whole sexuality was rooted in kink, to the extent that they had no interest in sex without kink. Marcie said:

I guess whenever I say sex I still think of $\mathrm{P}$ in $\mathrm{V}$, penis in vagina, because that's just what my brain thinks of as sex. But, like, if I'm having sex, if I'm enjoying it, there has to be spanking or discipline somehow involved, period.

Laura describes kink as her primary drive, a sentiment echoed by Lily and Marcie. In some cases, this drive supersedes interest in sex all together, which was true for four participants. As Marcie explained:

Once in a while, I'm like, "oh I could really use some sex right now," but, like, I haven't had sex... I don't know the last time I had sex, but I can tell you the last time I got spanked 'cause I'm like, "when is it gonna happen again?"

All participants expressed that they felt the common definition of sexual orientation relating to the gender of partners was limiting and often did not really apply to their participation in kink. Marcie describes her early experiences with sexual orientation:

I remember being confused about my sexuality when I was a preteen because I was like, "I don't feel straight and I don't feel gay, I don't feel like either." And I think the reason was because the representation of sex in the media wasn't of interest to me. What I was looking for, I couldn't find.

Other studies have found that the current three categories of sexual orientation (heterosexual, homosexual and bisexual) lack nuance and fail to take into account both fluidity 
of sexual orientation and sexual behaviour (Diamond, 2008; Gemberling et al., 2015; Klesse, 2014; Moser, 2016; Simula, 2012; Tweedy, 2012; Vrangalova \& Savin-Williams, 2012; Wilton, 2004). As a result, some scholars have argued that sexual orientation should be reframed to include activities that people can be orientated towards, such as kink (Better \& Simula, 2015; Gemberling et al., 2015; Hebert \& Weaver, 2014; Moser, 2016; Stiles \& Clark, 2011).

Of seven participants, three agreed that kink should be considered an orientation. The reasons for considering kink an orientation was that kink is a core part of who they are and a key component of their sexuality. Jessica says that some people are more "wired to be polyamorous" and that this could also be true for kink. Additionally, she added that her sexuality is a core part of who she is as a person:

I just identify as a fairly sexual person, and sex is just an important part of my life in whatever form it takes. So, for me, sexual identity is important to overall identity, and therefore kink would be an important part of my overall identity.

Laura said that she thinks kink is definitely an orientation of sorts but not necessarily a sexual one. For Laura, kink and sex are mostly separate, with most of her kink interactions taking place outside of any sexual and/or romantic context. For this reason, kink is separate from sex for her.

The remaining participants were hesitant to call kink a sexual orientation. Grace does not think kink is an orientation, but when asked to explain why, she had a hard time explaining further, saying, "my gut response is no." Grace explained further that for those like her who experienced an interest in kink early on, prior to being "sexual beings," that kink is "something deep within us."

Nicole framed kink as more of a tool she can use to express her sexuality but is "not something [she is]." Similarly, Brad said that kink is more an activity and would be akin to 
calling oral sex a sexual orientation for him. Lily mentioned that she does not think kink is a sexual orientation because it is not separate from straightness historically, adding that people can be both into kink and straight.

While participants were divided on whether or not kink should be considered a sexual orientation, five out of seven participants agreed that kink was at least a core part of who they are.

\section{Kink Origins}

Studies on kink have shown that an interest in kink typically appears at the onset of sexual activity or during puberty (Bezreh et al., 2015; Gemberling et al., 2015; Pascoal et al., 2015; Stiles \& Clark, 2011;).

Amongst my participants, there was often a difference of sometimes many years between when they were aware of their interest in kink and when they realized their interest in a particular gender. This is supported by a study that found an average of six years between when interest in kink is first realized and first kink experience (Pascoal et al., 2015).

Four participants mentioned noticing an interest in kink before the age of five or six. For these participants, this was either tied to their sexuality or predates when they were aware of their sexuality. Laura said that she's had her spanking fetish "since as long as [she] can remember." Participants interested in bondage or spanking said that the desire was not initially felt as sexual, but more as an intense interest and fascination with it. Marcie describes the discovery of her interest in spanking as such:

I don't know what word I would use... intrigued, I guess? By spanking. When I was, like, three years old or four, I have this, like, really vivid memory of being at a babysitter's house and, like, she was messing around with her sister and, like, one of them, like, was like, "if you keep misbehaving," to her sister, "like, I'm gonna give you a spanking." And, like, I'd never heard that word because my parents didn't believe in spanking. 
This origin story was similar with other participants who would notice scenes of capture or people being tied up in movies and books and become fascinated with it. Lily said she loved playing games that involved capture and would sometimes purposely get caught. Both Marcie and Laura mention a fascination with the word "spanking," which began with looking the word up in the dictionary. Marcie added that anytime the phrases "young lady" or "you're going to be in trouble" would appear in media or books, it would "turn on some light." For the participants interested in spanking or bondage, all would mention exposure to materials that depicted either activity as something that spurred interest. Of the materials mentioned, all were media or games typically aimed at children such as, Little House on the Prairie or playing Cowboys and Indians. Lily explained where her interest first started:

Just in my own thoughts, I guess, at that point and in TV shows and things. Books once I started reading, I really liked reading as a kid. And I always really liked the sections and stories where people got captured.

Laura and Marcie said that certain childhood books that had scenes with spanking are what first intrigued them.

Grace mentioned that she had a royalty fantasy where she was forced to show people her naked body when she was nine. For Grace and four other participants, an early interest in kink was detectable before an interest in a specific gender or genders, or in the case of Lily, before she knew she was trans:

I'm transgender and they'll ask you, you know, like, "oh, when did you know," or whatever and the stereotypical answer is, "oh, I've always known," or whatever, and I don't say that, like, that's not my answer for being trans, but I would say I've always known for kink. Like, as long as I've had desires that I can identify as sexual, they've been kinky kind of, like, just phrasing it broadly. They're sort of inseparable for me.

Kinky desires were noticed in childhood in five out of seven participants. The remaining two participants noticed an interest later in life. Access to resources and experience were cited as 
some potential reasons for this. Specially, participants cited that they simply were not aware of kink, due to living in a small town, or were only made more aware when they started to work in a sex store.

Brad mentioned that his partner only showed interest in kink when she experienced it firsthand:

For her, she wasn't really kinky at all until she had sex with somebody. I think like she said, like, a year or two ago and after she came, he told her that she was a good girl, and it just flipped a switch in her head.

Jessica said that she did not become interested in kink until she went off hormonal birth control at the age of 26. Jessica mentions that because she grew up in a small town in the early days of the internet, access to materials depicting kink was nearly impossible. She says that could have been part of the reason that she only noticed her interest later.

Jessica added that her overall interest in sex changed drastically when she went off hormonal birth control. She describes her sexuality when she was on birth control:

It was sort of almost disconnected from my, like, thoughts, so it wasn't like I could identify, like, "oh this specific thing, I'm attracted to this specific kind of person, or I'm attracted to this particular kind of sex," like I didn't have enough of a sort of mind-body connection.

Nicole explains that she only became interested in kink when she started to work in a sex store:

Well, certainly like sexual orientation-wise, like, I identify as bi and have been since mid-high school. When it came to kink it was really four years ago.

She explained that, overall, she had always had an interest in kink, but working in the sex store allowed her to get "the knowledge and words" about wanting to do kink. In contrast to the other five participants, these two participants did not express as much interest in bondage and/or spanking and were more interested in dominance and submission, as well as sadomasochism. While bondage and/or spanking were sometimes a part of their kinky activities, they were not the 
main focus. This is of note because, as mentioned earlier, the participants who were interested in bondage and spanking typically noticed this interest in childhood as a result of material that depicted those activities. The participants who were not as interested in bondage and/or spanking noticed their interest in kink in adulthood.

\section{b. Kink and sex/romance}

In my participant interviews, it was clear that there are many different iterations of kink, and it varies greatly from person to person. The simple question of whether or not kink is sexual got varied answers out of seven participants. Each participant had different structures and interpretations of how kink fit into their relationships and daily lives. For many, if it was not always a part of their romantic relationships, it was at least something that they considered to be a vital part of their expression of who they are, and any potential romantic partners would have to be okay with their participation in kink. Laura noted that she did not expect or even need her romantic partner to participate in her kink. She said it would be awesome if they did, but that finding a romantically compatible partner whose kinks also lined up is very difficult. She adds that the main thing is that her prospective partners need to be okay with her practising kink.

This idea was shared amongst most of my participants, and they would sometimes have multiple partners to fulfill different needs. Five out of seven participants said they were either polyamorous or had separate kink relationships, in addition to their romantic relationships. In some cases, the relationships that were centred around kink compatibility were completely nonsexual. Previous studies have found that kink play is not always done in a sexual context and that kink is often not done within the context of romantic relationships (Hebert \& Weaver, 2014; Newmahr, 2010; Simula, 2019a\& 2012; Sloan, 2015). These findings were supported in my 
participant interviews, with participants expressing many different motivations and relationship structures in which they practice kink.

Marcie stated that kink is of more importance to her than sex. When asked if she thought kink was a sexual orientation she said, "oh, a hundred percent. Yeah. No doubt in my mind." She explains how she views sex in relation to kink:

For years, sex wasn't even something I enjoyed or was interested in. I enjoy it now, but like I said, as a side dish, you know, it's like the coleslaw, like, I like coleslaw, it's good, but I don't go to the deli for coleslaw.

Lily explains that kink may not appear to be sexual, but that the energy exchanged feels sexually charged:

That's just how I experience it as sexual, and it seems to me, I'm not inside any of my partners' heads, but it seems to be sexual to them. Several of my play partners I've never had sex with, but I still feel I have some sort of sexual connection to these people because it's involving touching each other a lot too, like, regardless, you're sharing sort of these physical sensations. And there's people that I share physical sensations with as well that aren't my play partners, that are just friends. You know, we hug or hold hands or, like, maybe cuddle sometimes. But that is different, like, my relation to those people is different than the people that, you know, tie me up and hang me from the ceiling.

In these examples, kink is described not as an accompaniment to sex, but as an activity

and drive unto itself.

Laura stated:

Kink is my primary drive, it's a thing that I would say most focused on, and I heard one person describe it this way once. Another spanko said, "to me, sex and spanking are like cake and ice cream. I like both of them, but they're two different things to me, you know. I don't necessarily want them all mushed together." I'm a little bit in that camp, not quite as extreme as she was, but because I feel like I do need the power exchange to have a gratifying sexual experience. If I had to give up sex over spanking, it would be easy for me to say, yeah, spanking all day, all the time.

Laura adds that the majority of her spanking encounters are non-sexual. Marcie stated something similar, noting that when she goes to spanking conventions, she will get spanked by hundreds of 
people, including partners of her friends. She adds that getting spanked by her friends' partners is considered fine, but by contrast having sex with them would not be considered fine.

Three participants mentioned that in the moment kink may not be sexual but will provide masturbatory material. Marcie said that in the moment spanking is painful, and she does not enjoy it at the time. She continues:

But, at the same time, three days later, that memory is super sexual. When I'm at home in my bed alone, with my hand, super sexual.

Grace said that kink is often what she thinks about when masturbating and is her primary fantasy. Thus, while kink might not be perceived as sexual in the moment, it is often masturbatory fodder later.

Other participants felt that kink was explicitly sexual. Brad said that his kink practice was done with the intention of arousal for himself and his partner. Nicole said that because kink involves such intense sensations, it is more intimate than hugging or shaking hands. She explains:

I do think that kink is inherently sexual or even romantic because it's about trying to connect to a different level. You don't practise kink when you're walking down the street.

While kink was something that was paired with sexual activity for some participants, there was a large portion who felt that kink, even when it does not involve conventional sexual activity, definitely involves sexual energy. Many agreed that kink was how they expressed sexuality, and in the past, they did not feel sexually fulfilled when kink was not a part of their life. For some, like Jessica, kink allows them to cope with chronic pain, which prevents conventional methods of expressing sexuality:

I don't know, for me it's very much about sexual arousal, sexual response, especially since chronic pain has been more of a barrier in sort of traditional sexual practices for me. Then it's even more a very specific sexual erotic, practice that I do specifically for sexual gratification. Because I can't always participate in sort of more conventional forms of sex, because of chronic 
pain. So, for me, kink is very much sexual, and it's almost a replacement for sort of traditional penetrative sex.

In these instances, kink is a way to access connection and intimacy. For four participants, kink is an important expression of love and affection with partners. When asked if they would choose a vanilla relationship or a kinky one, three participants said they would choose a kinky one, while the remaining four said that as long as they could have kink in some other capacity, they would be fine with a vanilla relationship.

Grace is currently in a full-time mistress/slave relationship. When asked if the relationship is romantic and/or sexual she said a definite yes. She explains that one of the potential benefits to kink being a sexual orientation would be:

Sometimes I would like it to be more normalized because I want to talk about my relationship more openly with people. I'm in love.

She explains further that, due to the stigma surrounding kink, she often cannot fully talk about her relationship with other people.

Nicole noted that she has tried practising kink in a romantic/sexual context and in a nonromantic context and mentioned that the latter is harder because establishing boundaries and the context of the relationship can be more difficult. She also mentioned that it provides a bigger challenge intellectually. Laura has been with the same Dom for over five years, but their relationship is more a deep friendship than a romantic relationship per se. She said that they explored turning things into a romantic/sexual relationship but did not feel that it was the right course of action.

In interviews, there was a range of relationships and expressions of kink. For some, like Brad, kink was exclusively for romantic/sexual partners. For others, kink was separate from romantic relationships and was a drive unto itself. Generally, participant interviews support 
existing literature that demonstrates that there are many different meanings and interpretations of kink and kinky relationships.

\section{c. Legal Benefits}

Previous studies have found that BDSM practitioners are subject to discrimination in relation to employment, child custody and within the criminal justice system (Bezreh et al., 2012; Gemberling et al., 2015; Meeker, 2014; Wright, 2010). In one study on how open practitioners are with their interest in kink, it was found that more than half of respondents concealed their practices from the majority of people in their lives (Stiles \& Clark, 2011). Participants in my study were asked what they thought the potential benefits of considering kink a sexual orientation would be. While participants were divided on the question of whether or not kink should be considered a sexual orientation morally, most agreed that if it was considered a sexual orientation legally, there would be substantial benefits with regards to the Human Rights Code and education. Brad explains:

I studied human resources in grad school, and I think it would be great to see some of the discrimination protections that are extended to sexual orientation, though those are woefully inadequate in the US, still extended to kink, if you were to consider kink to be a sexual orientation.

In my interviews, there was a variety of responses to the question of whether or not they faced discrimination. In general, participants who inhabited less traditional jobs, or jobs that were either directly related to sexuality or were sex-positive, did not feel that they faced any discriminatory consequences. Nicole, who previously worked in a sex store, said that, overall, she has not faced much discrimination herself:

I have had circumstances where people have asked me in negative ways, trying to make it seem like it's a bad thing or, "well, of course I would be into beating people," and blah blah and trying 
to make it some sort of weird twisted judgment, and in those cases I don't respond, I'm like, "meh, I don't owe you an answer."

She adds, however, that through her involvement in her local kink community, she has witnessed others who have lost jobs or had charges laid against them for consensual kink. She says that, overall, she has been very lucky not to encounter either of those consequences. Laura said that she could have gotten fired from some previous jobs if she was open about her involvement in kink, but that with her current job, it might just make her workplace more uncomfortable.

Participants who worked in more traditional fields, such as office work and in education, felt that they had to keep their participation in kink quiet, lest they lose their job. Marcie expressed:

You know, as of right now, my sexual orientation could get me fired. One of my exes legitimately said something to the effect of [that]. I told him about my kink, and he basically said that it sounded like I was a pedophile. So, I want to be able to be me and not have to worry about my job.

In this instance, a previous partner was using misconceptions and an unflattering comparison to a disorder found in the DSM and a criminal offence. Due to lack of understanding, and, in these examples, clear prejudice against kink, it is easy for people, and especially jilted exes, to claim that someone is guilty of criminal offences, when the framework for understanding kink is tainted by an association with criminality and pathology. In some instances, participants spoke about kink being likened to abuse. Brad speaks about this fear with regards to a past partner:

"[Participant's name] loved to slap me or spank me, choke me, that sort of thing." Sounds pretty terrible, and it's hard for people to grasp that was a consensual thing that we discussed at length. And especially because kink is still really taboo and is looked down on, and I mean, the idea of consensually hitting somebody is not, it's hard for people to even begin to grasp. Knowing that could happen scares the crap out of me. 
All participants felt some need to hide their BDSM practices for one reason or another.

Grace mentioned that certain types of kink play are technically illegal and can be punished under the law:

Your forms of protection under the Human Rights Code. We could get rid of the idea that we could be arrested for practicing in impact play. You cannot legally hit someone, it does not matter.

Participants agreed that considering kink a sexual orientation could legally benefit them. In particular, this could alleviate fears of job loss or criminal charges of assault.

\section{Kink Culturally}

In this section, I will discuss how kink is framed culturally. Specifically, I will examine how kink has been framed as serious leisure and if this theory aligns with my participant interviews. Further, I will explore similar origin stories and the creation of a community through similar kinks. Next, I will discuss how public opinion of kink influences the treatment of kinky individuals. Finally, I will examine the question of whether or not kink should be considered queer.

\section{a. Kink Communities}

Newmahr (2010) argued that kink was more similar to serious leisure than it was to sexual orientation. Both Newmahr (2010) and Weiss (2006) noted in their ethnographies that within kink communities there was an emphasis on acquisition of skills and tools in order to participate in kink. Nicole agreed with this comparison saying:

I think the big part of it is kink requires research. It requires taking the time to really think through what you're doing and what you want to do. I never had to do research on being bi. I felt I was bi and confirmed it in my own way and then I existed as that person.

She continued that kink needs research due to safety concerns: 
So, I do think that a disadvantage to people just, "uh, that's the way I am," is that there can be a bit of a flippancy about it. It can be dangerous. It's not dangerous to be bi.

This statement was echoed by other participants. Brad said that because kink involves a lot of transgression of boundaries that education and safety are crucial. Lily said that in her early experiences with kink she lacked the knowledge to safely negotiate boundaries and consent, which unfortunately resulted in her being in more dangerous situations. Therefore, the stipulation that kink is serious leisure and requires some knowledge acquisition does appear to have some footing in kink practitioners' experiences.

Participants explained that kink is more to them than simply pleasure or an expression of their sexuality. While both of these were mentioned as important, there were a variety of reasons why their interest in kink was important to them and something that they sought out. In many cases, kink is a lifestyle. Laura mentions the shared experiences and sense of community:

You know these people have had the exact same thoughts I've had, the same experiences, so it's very much like, "I'm a person who's kinky because, sure, I have these desires, but this is also how I interact in the world." And I wonder if I had tucked it away and hadn't engaged, if I would feel that way.

This participant frames kink as a way that she interacts with the world on a whole, not just in the context of a scene. Both Laura and Marcie identify as spanking enthusiasts, or spankos as they refer to themselves. Spankos form a global community that hosts conventions, play parties and various other gatherings all over the world. For both Marcie and Laura, this community is a vital part of their social life and a chance to be with like minded people. For these participants, kink has a strong community aspect that fosters a sense of unity. Marcie and Laura mention that by participating in the spanko community, they have learned that there is a similar origin story across the globe. Marcie explains:

But the fact that all of us have that same script, and there are people in our chat group that are in Australia, there are people in our chat group that are from you know the UK, people from all 
over the States, you know. New York, and Texas and Jersey and Pennsylvania and Indiana and California and Arizona and all over the place, you know. And it's like, "how does that happen?"

Laura agreed that spankos have a very similar origin story with regards to discovering their interest in spanking. Both participants mention that it is common in the spanking community for people to become fascinated with the word spanking itself, often looking it up in the dictionary and seeking it out in books.

Both Laura and Marcie regularly attend spanko events, adding to the theory of kink as serious leisure. Marcie describes one such party:

So now I go to national parties sometimes and, like, next week I'm actually going to be at a really big party called Cheeky, which is Cheeky Preparatory Academy. It's a school event, so the whole thing's roleplay, and I dress up in a schoolgirl uniform. They have this whole building, and you rotate to go to classes, and you have a schedule, and we have homework. The people who go continuously go, so you have the same classmates and the same teachers and the same deans, and it is such a good freakin' time.

Three other participants mentioned attending play parties or other community events as an expression of their interest in kink. Nicole said she often bases her interest level in kink in relation to how involved in the kink community she is at the time. Lily mentioned that she often attends rope bondage events for both practice and play purposes. In many of these events, sex does not take place and is not the focus. Laura said, "I would say that $98 \%$ of my interactions that are BDSM/kink oriented do not end in any sort of sexual contact."

As mentioned above, one participant stated that being spanked was not considered the same as having sex, for the purposes of fidelity within monogamous relationships. She added that this could be due to perceived taboo and stigma surrounding purity and sex, whereas spanking does not quite fit within that narrative and is already something that is seen as taboo. 
These examples show kink from a community standpoint. While some participants did mention the sexual energy that is present for kink activities, these examples support the idea that kink can be separate from sex, and, in many cases, is a form of community expression.

\section{b. Need for Education}

Education and access to resources were commonly cited as a benefit for kink being considered a sexual orientation. Many participants mentioned that learning about kink when they first developed an interest was difficult, due to lack of resources or resources that were difficult to access. Additionally, three participants mentioned that they put themselves in dangerous situations simply because they had no other option to learn about kink and/or did not know how to safely engage in kink. Marcie said that she has traveled long distances to meet up with another spanking enthusiast she had only interacted with online:

When I was 19/20, I went a little crazy and just started meeting lots of people from the internet 'cause I was just like, "all these people, they get me," and I kind of, like, overdid it? To the point where like I, like, got on a Greyhound bus to go to San Francisco to meet with a girl who drove to me Oregon, and it was with a bunch of people, and it was tons of fun, and thank god, I wasn't murdered but probably wasn't the safest thing to do.

She says that luckily nothing bad happened to her when she did things like this, but they very easily could have. Lily mentioned that discussing consent and boundaries was an issue in her early kink experiences:

I do think it should be more prominent, and there should be more open discussions about kink as an aspect of sexuality alongside sexual orientation. I would have been in a lot less dangerous situations growing up if I'd known what kink was and known how to negotiate consent.

Three participants either directly mentioned or alluded to similar situations from early kink partners. Most situations were a result of bad communication or unsafe practices. No participants explicitly mentioned any illegal or physically abusive behaviours, but they did 
mention being in potentially dangerous situations. Anecdotally, it is common when someone, especially female, creates a new profile on the kink social media site FetLife to get flooded with messages from so-called 'experienced' older men, telling them that they can 'show them around' or teach them the ropes, so to speak.

The reason that so many participants said they put themselves in these potentially dangerous situations was that they felt there was no other way for them to learn and experience kink. In many cases, participants grew up in smaller towns or, in one case, a very religious household, where access to kink was limited and sometimes forbidden. This meant that in order to gain experience, many would have to do so in secrecy. It also meant that many participants were at the whim of whoever they were practising kink with to educate them and not abuse them. Grace describes one of her early experiences:

Because at the time that I made that I had my ah-ah moment, I was sort of informally pledged to a dominant online, who, whom I would have to reach out to for permission to pleasure myself. I was going to ask this dominant for permission to get off, and I hadn't gotten off for a week, and I was feeling it. And she never got back to me. She was busy, she never got back to me with permission.

Participants noted that their discovery of kink was often hampered by social stigma from peers and partners. Two participants, in particular, would go through binge and purge cycles with kink. Grace felt during her purges that she was being a better person and spoke of her interest in masochism and submission more in terms of an addiction she needed to quit. In both instances, she would eventually return to kink through online forums and searching for kink photos and videos. She explains:

I think it was a few months before I was lurking porn sites again. We almost broke up a couple times, and when we did, I always think, "okay, I'm going to get back into kink now, I'm gonna," and but then we didn't break up.

Laura describes a similar experience: 
'I'm not going to look at this anymore, I'm going to be quote unquote 'good,' I'm not gonna do this, I'm gonna be the person I'm supposed to be." But I would continuously come back, come back to, you know, seeking out things and books, and a very classic kind of spanko trope is looking up "spanking" in the dictionary and "discipline" in the dictionary, and all those things. Like, could not stop, I just kept coming back to it, and once I got to the point in college where I was ready to explore, I'd done a lot of soul searching.

Both participants felt strongly that there was something wrong with them that they needed to cure. In each case, the reason for this feeling was due to outside perspectives, namely from peers that were strongly against kink. In Grace's instance, it was her former partner who thought that kink was against women's rights and was acting out the patriarchy in the bedroom. For Laura, it was purity culture that denotes that women need to be pure and virginal before marriage.

Instances like this could be avoided if there were better education and resources widely available surrounding kink. The negative thoughts surrounding kink and resulting stigma described by participants was usually due to misinformation surrounding kink. As Brad said: “because our sexual education is really piss poor anyway, but, you know, a lot of people don't learn about kink and then, therefore, don't learn about kink safety, especially because a lot of kink involves transgressing boundaries consensually."

Currently, there are no places outside of sex stores or online that provide kink education or workshops. The issue with both of these methods is that they are not regulated, and the information provided might not be accurate. The other issue is that they are not always accessible to everyone. Sex stores arguably would provide the best resources and most accurate information; however, in most cities you need to be at least 18 years of age in order to enter or participate in workshops. Additionally, most workshops and resources at sex stories cost money, which not everyone is able to afford. Nicole notes: 
If you're wondering about STDs and STIs, there are places, real places, even online or in person. And [you] know that the information you're getting is true and accurate. There are very few places for kinksters to do that because it's not something that is recognized as a part of people's lives. It's recognized as something that's kind of shady.

In relation to many kink practices, especially those that involve more intense and potentially dangerous activities, this is unnerving. This leaves room for potential psychological and physical harm for those who are just learning or getting into BDSM. Not to mention, this makes it easy for abusers and predators to prey on the new and naïve.

Grace mentions that having kink as a sexual orientation could also help open kink up to critique. This would mean that there could be more open discussion surrounding healthy relationship dynamics and practices within kink. She says that because so much of kink is stigmatized, it results in kink practices not being critiqued in open forums and any critique is thought to be discriminatory.

Negative public portrayal was the most frequent form of discrimination brought up. Marcie said that when she is on dating sites, there is a misconception that because she mentions her interest in spanking, she is automatically promiscuous and interested in having sex with anyone who messages her. Nicole mentioned receiving judgmental looks and comments from other people. Other participants said that they were careful who they told about their interest and participation in kink, due to fear of stigma and potential job loss.

Speaking from my own experience, in both writing this thesis and doing this research in general, that is the underlying fear I have when I disclose what I research. As an experiment, I did go on a dating site and put what I research in the bio. The result was as expected, whereby many of the men who would message me would bring up my research very quickly. It would typically start out friendly and they seemed genuinely interested in my research. However, usually, very shortly after this, they began to ask me very personal and intimate questions about 
my sexual interests and sex life in general. While this might be a generalization and could use more research, my anecdotal experience, paired with what I've heard from my participants, shows a general trend that has been documented in various studies regarding kink and discrimination (Gemberling et al., 2015; Iannotti, 2014; Moser \& Kleinplatz, 2006; Stiles \& Clark, 2011; Wright, 2008 \& 2006). In my experience and in my participants' experiences, disclosing interest in kink is typically interpreted as an invitation to have more sexually explicit conversations. Marcie said that on online dating she is often treated "like a walking Fleshlight," referring to the sex toy that simulates vaginal intercourse aimed at men.

Overall, the perceived benefits were that there would be more education and resources surrounding kink, which could then alleviate social stigma. Additionally, considering kink a sexual orientation would allow for more legal protections, which could alleviate fears of job loss or other consequences.

\section{c. Is kink queer?}

Is kink queer? The term "queer" generally means non-normative or sexuality that is outside of what is considered to be normal (Callis, 2016; Sprott \& Hadock, 2018), although the term sometimes it is also used as a shorthand for LGBT. Some studies have argued for the inclusion of kink within the framework of queerness and have made the comparison to other LGBTQ+ identities (Gemberling et al., 2015; Moser, 2016; Sprott \& Hadock, 2018; Tweedy, 2011). There are many variations on the use of the word, and definition varies from person to person. In participant interviews, the question of whether or not kink should be considered queer was broached when discussing the detriments of considering kink a sexual orientation. The consensus amongst participants was that kink was not necessarily queer and that considering it so 
would be taking away from the discrimination and struggles faced by many gay rights activists in the past. Lily explained that because kink is not a visible trait, someone can still hold structural privileges, such as being white or a man. She explains further:

I don't think kink is a sexual orientation because it hasn't historically [been] separated from the straightness. I think that's what it is, like you can't be gay and be straight, basically, you can't fit within that sexual norm. I encounter a lot in the kink community are people that, you know, fit within that norm, you know, have a house and two kids and a dog and a cat, not that gay people can't do that, but, you know, you get side-long looks from your neighbours.

What she is alluding to is structural privilege gained through fitting visible norms. Historically, being queer has been separate from these norms. As many participants have mentioned, kink is generally something that can remain hidden from society. While the activities and sexual expression itself might be non-normative and in that sense are "queer," the surrounding structures and social locations can mean that someone is otherwise normative. This is something that many participants brought up during interviews that, while they might identify personally with kink being a sexual orientation for them, they felt that, politically and socially, it would be disingenuous to the queer and gay rights movement. Some participants mentioned that there are some key differences historically in relation to queer history and kink history. Within the context of queer history, several participants mentioned the violence and marginalization faced by queer people. Laura notes:

I think sometimes that it takes away from some of the marginalization and some of the violence that LGBTQ+ individuals have suffered and have experienced, and I think there's so much work to do, you know, for queer individuals. It's just, like, there's enough on that plate. When I think about policy changes, when I think about things that need to happen, like, that's the priority.

Lily said that she would worry that it would take away from the work that still needs to be done within the queer community, especially in places where being out and queer is still dangerous.

There's never been a purge of the Canadian civil service, "alright, who's tying each other up? What if a Soviet ties you up and takes the secret documents?" That's like... it's not a thing. I think it is a disadvantage. It confuses the way in which we remember and address going forward 
[from] systematic discrimination that's occurred against gay and lesbian people. We still have to dismantle a lot of the way that our society pushes compulsory heterosexuality.

Laura expressed a similar sentiment, that queer communities "already have enough on their plates." Lily said that adding kink to the definition of sexual orientation legally could cause some difficulty with affirmative action schemes, saying:

The idea that we have someone that's gay at the table, someone that's lesbian at the table, you don't necessarily need someone that's kinky at the table.

Participants felt that if kink were considered an orientation, then the comparison to the LGBTQ+ community would be made, which could possibly equate the struggles of both communities. Jessica mentioned that she thinks some of the pushback against kink is in relation to making the LGBTQ+ movement "less respectable," but adds that she can understand where that thinking comes from:

I can also have some sympathy for where people who make those arguments are coming from, where if they're already struggling for even basic acceptance, especially in certain parts of the world where being LGBTQ is still really stigmatized.

Participants were quick to add that they did not feel that people who are kinky faced the same level of discrimination and stigma as those in the LGBTQ+ community. Grace said that, for her, it simply does not come up; therefore, she has not faced much discrimination for it. It was added that, for most people, a kinky identity is often something that can be hidden, of which otherwise privileged groups can be part. Two participants said that, for them, it simply does not come up and that they feel that their kinky identity is something that they want to keep private. Laura said:

But, you know, it's just something that I have no desire for most people to know about me. Whereas my sexual orientation, I would love if I could be out to everybody you know.

Lily added that she faces far more discrimination due to her trans identity than her kinky identity. Overall, participants felt that politically kink should not be equated to the struggles and 
discrimination faced by the LGBTQ+ community. Many participants either had personal experience as members of this community or were versed in the history of queer activism. Therefore, the consensus was that a detriment of kink being considered a sexual orientation would be that it could potentially equate the violence and discrimination faced by the LGBTQ+ community to that faced by the kink community. Participants explained that, by comparison, kink practitioners have not faced the same level of discrimination, and, in many cases, are still members of privileged groups and can therefore remain hidden.

\section{Trans Perspectives}

\section{a. Perceived Discrimination}

Previous statistics on discrimination and kink lack trans perspectives, with most either having no trans participants or not disclosing if they do (Meeker, 2013; Iannotti, 2014; Stiles \& Clark, 2011; Wright, 2006). Surveys done by the National Coalition for Sexual Freedom did have trans respondents but did not note any differences in how they responded to questions in comparison to cis participants (Wright, 2008). The exception to this is German scholar Robin Bauer (2008) who has done extensive ethnographic research within trans and queer kink communities. Bauer's work almost exclusively focuses on queer and trans communities but notes in his work that he has a unique advantage in being a part of those communities himself (2008; 2010). Therefore, he is granted access, whereby other researchers either simply do not have access or overlook these groups.

The answers regarding discrimination faced for being kinky differed in trans participants in comparison to their cis counter parts. In general, my trans participants did not feel that they 
experienced discrimination due to their interest in kink and instead stated that, for the most part, it was hidden and part of their private life. Grace explains:

Well, it doesn't come up. I don't go around talking about it, how can I face discrimination for it? I don't bring it into my everyday life, other than the permissions that I need, and I keep that to myself.

Lily mentioned that due to her visible trans identity, anyone who associates with her generally is more accepting of queerness and, by extension, is often fine with kink:

I know that, in the abstract sense, I've met them on the internet. People have negative views on everything on the internet, so I do discount [it]. I've never met anyone in person who's like, "oh, you do kink, that's disgusting," or anything like that because I think just the selection of the person that I am ... the people that are willing to [be] friends with a weird transsexual, like, are generally people that are okay with kink, I find.

Both trans participants in my study said that, overall, they faced more discrimination for their trans identity than they did for their kinky identity. Lily mentioned that because she is visibly trans, she will often receive more harassment for that, as opposed to her other identities, such as being queer:

I get much more harassment based on looking trans than in having a female partner, but that might also partly be because I'm identifiably assigned male at birth, so I think of a lot of people, they're like, "oh, at least you have a girlfriend."

She adds that if someone knows she is kinky, it is typically because they are practising kink together, therefore it is not something that she shares with everyone she knows. Grace mentioned a similar perspective, that the people who knew about her interest in kink were her closest friends and those she practises kink with. Neither Grace nor Lily felt that there was a need to have more people know about their interest in kink.

In comparison, cis participants expressed more fear in relation to discrimination, as well as more overt instances of discrimination. Nicole explained the discrimination she has witnessed within her kink community: 
Technically, you can still get fired from the government if they catch you, that you do kink in your private time, [even] consensually. I've talked to lots of people in the community and former customers that have partners break up with them, they've had people try to charge them, even though it was consensual. Even my male partner right now, he's dealing with an issue where he was in a relationship for a few years, it was very toxic and very bad, and he's still feeling the repercussions of it because she is accusing him of things that he didn't do.

Two other cis participants expressed similar fears of job loss and discrimination faced socially for their interest in kink, as was mentioned in the section discussing legal benefits. Both Brad and Marcie felt that their interest in kink was something that could potentially threaten their jobs. For this reason, both were in favour of kink becoming a sexual orientation to grant them legal protection from such discrimination.

The same fear of job loss was not expressed by the two trans participants, who felt that their interest in kink generally did not come up in the workplace and therefore was not a threat to their employment.

In this sample, there appeared to be a dichotomy of perceived and experienced discrimination between cis and trans groups. From this small sample, it would appear that more privileged groups experienced and feel more kink-related discrimination on average. However, this would be worth further research to see if this is in fact an accurate assumption. As mentioned earlier, the trans participants in this study generally found that they were accepted amongst their loved ones for being kinky because they surrounded themselves with people who were more accepting of trans identity, and, by extension, were often accepting of kink as well. A hypothesis could be that those who belong to a visibly marginalized group might perceive less discrimination from something as hidden as kink because they face more overt discrimination for other identities that are more visible, such as transness or race. More research would be needed on the intersection between marginalized groups and kink and discrimination, in order to determine if this is accurate. 


\section{b. Gender Identity}

Previous research has found that kink is often used as a safe space for gender nonconforming people to explore gender (Bauer, 2008; Simula, 2012). Other studies have found that within the context of sexual orientation, kink interest often transcends gender and that kink compatibility is more important (Dancer et al., 2006; Simula, 2019a\&b; Sloan, 2015).

These theories were supported within my study by the two trans participants interviewed. Their relationship to kink was unique in terms of both their discovery and lived experience of kink. In particular, their relationship to kink and expression of kink were very closely related to their lived experience as a trans person. Lily explains "And it's interesting because all the ways in which my gender and sexuality are non-normative sort of bleed together in a lot of ways."

This sentiment was repeated throughout Lily's interview. She said because her gender identity was already considered to be non-normative, the fact that her sexuality was also nonnormative simply fit. She explained that living as a visibly trans woman acted as a sort of litmus test for future partners and friends, especially in relation to discrimination. She adds that her trans identity and kink identity are closely related because she started discovering them both around the same time. Lily explains this by using a metaphor: "It started untangling like a ball of string, you know, if you're untangling one bit, that leads you to untangle the other bit."

In past studies, kink has been theorized as a means to safely explore gender (Bauer, 2008). In a study regarding queer and trans involvement in BDSM, many participants mentioned that BDSM allows them to escape from the struggles they face in everyday life and questions cultural assumptions of power with relation to gender (Bauer, 2008). Grace expressed similar experiences with kink: 
Kink was a way for me to express femininity in a safe context. And I've heard this is common for a lot of trans women. If you took a sample of a random trans woman, there's a greater percentage of kinksters among them than the general cis gender population because kink gives us a way to... I mean, it's not only safe from society, it's safe from ourselves as well.

Grace's first foray into kink was through what is called 'sissy' play, whereby male-identified practitioners are humiliated and degraded using traditionally feminine actions, insults and clothing. This could include wearing women's clothing, being called things such as "bitch" "pussy," or "sissy." Grace would read and consume pornography and other content with the storyline of forced femininization, meaning that a male-identified participant is "forced" to dress and act feminine. However, this changed when Grace started to realize that she was, in fact, a woman herself.

She describes one of the catalysts for realizing her trans identity:

Because at the time that I made that, I had my ah-ah moment, I was sort of informally pledged to a dominant online, who, whom I would have to reach out to for permission to pleasure myself. Um, and my ex was going to take our son on a weekend camping trip, and I had opted not to go. And I decided that I was going to wear women's clothing the entire time they were gone, I was going to wear it to sleep, I was going to wear it all day long, it was going to be big sexy and exciting, and I was going to ask this dominant for permission to get off, and I hadn't gotten off for a week, and I was feeling it. And she never got back to me. She was busy, she never got back to me with permission and so I just sat there, and the longer I sat there without jerking off, the longer I thought, "wait, this is really nice, I'm just sitting around in my dress."

After doing some reflection, Grace realized that she was no longer into sissy play and was actually a woman: "I usually say submissive cross dresser, but I was on all the sissy sites. And the moment I realized that I'm actually a woman, that very day I flipped.”

For Grace, kink was a way to express her true identity as a woman. It was and still is closely enmeshed with her sexuality. The same is true for Lily, who feels that her trans identity and kink are intertwined and cannot be separated. For these participants, kink is something that is deeply connected to who they are and their gender. 
Outlined in this chapter were the findings from interviews. Overall, participants felt that kink should be considered a sexual orientation for the purpose of legal protection. Additionally, many felt that kink is in need of more accessible education and resources. These were cited as benefits to considering kink a sexual orientation. Otherwise, participants were divided on whether or not they felt that kink should be a sexual orientation. Within this study, there is evidence to suggest that kink, in some cases, is an immutable trait. Discrepancies arose when asked whether or not kink was considered sexual to participants. Many classified kink as either an addition to sex or something that was completely separate. In terms of detriments, many participants felt that comparing kink to queer communities was not fair, due to the historic violence and discrimination queer communities have faced. For these reasons, the consensus is that kink is a type of orientation, but not necessarily a sexual one. 


\section{Chapter 5: Conclusion}

This thesis sought to explore whether or not kink should be considered a sexual orientation and to evaluate the benefits and detriments of such a framing. In order to answer this question, seven participants were recruited from Canada and the United States for interviews. These participants were asked questions regarding their interest in kink, how they defined sexual orientation and overall if they thought kink should be considered a sexual orientation, and if so, in which contexts.

This study aimed to add to literature surrounding both kink and sexual orientation. Recent literature on sexual orientation is increasingly seeking to expand the definition and criteria for something to be considered a sexual orientation (Diamond, 2008; Gemberling et al., 2015; Moser, 2016). Specifically, scholars have argued that sexual orientation should include more than just gender-based attraction. (Diamond, 2008; Moser, 2016; Tweedy, 2012). Some have made an argument that other erotic and intimacy interests, such as polyamory or kink, should be included within the framework of sexual orientation (Dancer et al., 2006; Gemberling et al., 2015; Klesse, 2014; Moser, 2016; Stiles \& Clark, 2008; Tweedy, 2012). The findings in this study supported the argument that the definition of sexual orientation should be broadened beyond gender-based attraction. Some participants explained that the existing definition of sexual orientation did not resonate with them and their kink practices.

However, participants were divided on whether or not they thought kink should be considered a sexual orientation. Many participants cited noticing an interest in kink at a young age, which aligns with existing literature that suggests sexual orientation is often noticed prepuberty or in some cases at puberty (Kinsey et al., 1948; Moser, 2016; Shively et al., 1984; Yost 
\& Hunter, 2012). Most stated that kink was at minimum a core part of who they are, which is consistent with findings in other studies (Bezreh et al., 2012; Brame et al., 1993; Dancer et al., 2006; Stiles \& Clark, 2011; Yost \& Hunter, 2012). However, only a couple felt that kink was a sexual orientation. Part of this was because of the limited definitions of sexual orientation cited by participants as sexual attraction based on gender. Many participants stated that they felt that kink was sexual or at least had sexual energy, but would nonetheless classify it differently than their definition of sex. Therefore, most participants felt that kink was either a tool they could use to express their sexuality or a separate orientation that is not necessarily sexual.

From a legal standpoint, all participants in this study agreed that considering kink a sexual orientation for official purposes would afford more protection from discrimination. This supports previous studies that have collected data on instances of discrimination faced by kinky people (Bezreh et al., 2012; Gemberling et al., 2015; Meeker, 2014; Wright, 2010). Past studies have shown that kinky people often face discrimination in the form of job loss, child custody battles, harassment and negative public portrayal (Bezreh et al., 2012; Brown, 2010; Gemberling et al., 2015; Meeker, 2014; Wright, 2010). While not all of these were mentioned in interviews, participants did mention fear of job loss and assault charges, harassment and general negative social portrayal. These experiences were mentioned as motivation for kink to become more socially acceptable and potentially to have legal protections. This was also the most mentioned benefit to considering kink a sexual orientation. Even if participants felt personally that kink was not a sexual orientation according to their own understanding of the concept, all agreed that legally considering kink a sexual orientation would be beneficial to help lessen discrimination and stigma. 
Participants mentioned a need for better education and resources surrounding kink. The above-mentioned instances of discrimination were often due to poor education and misconceptions surrounding kink. Many participants mentioned previous partners pathologizing their interest in kink and framing it as something that needed to be cured. Additionally, participants revealed that their early forays into kink would often put them in dangerous situations because they saw no other option. Therefore, safe and reliable sources of information for kink was cited as a need within society. This was the second most cited benefit to considering kink a sexual orientation.

One of the main reasons participants in this study were hesitant to call kink a sexual orientation was due to equating a kink identity with a queer identity. The majority of participants in this study identified as members of the queer community and were aware of past struggles faced by queer communities in terms of discrimination and violence. Therefore, these participants felt that labelling kink a sexual orientation could cause some to equate the history of violence and discrimination faced by the LGBTQ+ community with that of the kink community. Some participants were adamant that their queer identity or trans identity lead them to face more outward discrimination and that overall there is still more work that needs to be done with regards to LGBTQ+ rights. As a result, most participants felt that in comparison those who identify as kinky have faced far less discrimination than the LGBTQ+ community and it would be insulting to compare the two.

In this study two participants identified as trans. Their relationship to kink and their perspectives on discrimination were unique and worth exploring. In relation to discrimination, the two trans participants felt that they faced far more discrimination due to their trans identity than their kink identity. In general both felt that their kink identity is not visible and therefore 
does not come up unless it is with someone who they are practicing kink with. Whereas some cis participants detailed more experiences with kink-specific discrimination.

This study identified a few areas for further research. Firstly, although this study had an admittedly small sample, there appears to be a discrepancy in experience of discrimination between trans individuals and cis individuals. I have suggested a couple of possible explanations for this. One is that visibly marginalized groups might face more overt discrimination for other identities such as race or gender, therefore making any kink-related discrimination they face seem less obvious or less urgent. Another possibility is that due to occupying a more marginalized lived experience in general, these individuals typically surround themselves with more accepting people. Both of these theories were mentioned by trans participants in this study. However, a larger sample would be needed to examine if this is a universal experience.

As many studies in the past have mentioned, participants in kink-related research studies are typically white, middle class and well educated (Bauer, 2008; Gemberling et al., 2015; Newmahr, 2010; Simula, 2019a; Tripodi, 2017; Weiss, 2006). While I did have two trans participants, there was no racial diversity and all participants were well educated. Therefore, diversity was still lacking within my study. This is a significant weakness that must be acknowledged. Future research in this area should consider proactive strategies to reach racialized and Indigenous kink practitioners so that whiteness does not come to stand in for what constitutes as the kink experience. In addition, further research should seek to reach other marginalized groups' experiences to further understand the complexity and diversity of kink identities and experiences of stigma and discrimination that intersect with kink-phobia. 
While the findings in this study do provide some interesting insight into kink and sexual orientation, this is only a snapshot of the kink community. Therefore, for future research a larger sample size would be useful to compare and contrast these findings.

Overall, there are more avenues for future research regarding the framing of kink as a sexual orientation. This study provided valuable information regarding how some kink practitioners define sexual orientation and their thoughts on if kink should be considered a sexual orientation. These interviews provided useful insight into the benefits and detriments of considering kink a sexual orientation. Through this study, I was also able to see the gaps that exist in research and populations that are underrepresented in kink research. Notably, through my interviews with trans participants, I was able to witness how marginalized identities responses might vary greatly in terms of discrimination. It is my hope that the research provided will be used to further explore how kink practitioners frame their lived experience and if labelling kink a sexual orientation would ultimately aid in reducing stigma faced by kink practitioners. 


\section{Appendices}

\section{Appendix A: Participant Demographic Data}

\begin{tabular}{|l|l|l|}
\hline Name & Sexual Orientation & Kink \\
\hline Brad & Mostly Heterosexual & Various \\
\hline Lily & Queer & Rope Bondage \\
\hline Nicole & Bisexual & Various \\
\hline Jessica & Bisexual & Dom/sub \\
\hline Grace & Lesbian & Dom/sub \\
\hline Marcie & Heterosexual & Spanking \\
\hline Laura & Bisexual & Spanking \\
\hline
\end{tabular}




\section{ARE YOU A BDSM \\ PRACTITIONER?}

\section{INVITATION TO PARTICIPATE IN A BDSM/SEXUAL ORIENTATION STUDY}

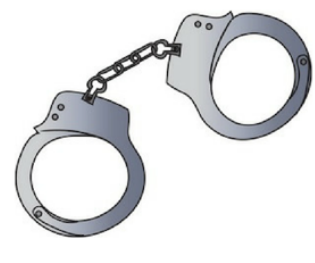

To participate you must:

- Be over 18 years old

Be a BDSM practitioner for over 6 months

Participation in this study involves:

- An interview of 1 hour with a maximum of 2 hours

Or

\section{- A short online survey}

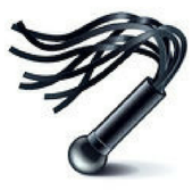

The goal of this study is to gain more insight into whether or not kink should be considered a sexual orientation. This study will explore the potential benefits and detriments of kink being considered a sexual orientation, using personal experiences of BDSM practitioners. Additionally, the goal is to potentially help reduce stigmas that surround BDSM practitioners and reduce discrimination.

TO FIND OUT MORE ABOUT THIS STUDY PLEASE CONTACT CAITLIN HART AT CAITLINHARTQCMAIL.CARLETON.CA.

THIS RESEARCH WAS REVIEWED BY THE CARLETON RESEARCH ETHICS BOARD AND HAS RECEIVED ETHICS CLEARANCE (REB \# 109375). IF YOU FEEL YOU HAVE NOT BEEN TREATED ACCORDING TO THE DESCRIPTION IN THIS FORM, OR YOUR RIGHTS HAVE BEEN VIOLATED DURING THE COURSE OF THIS RESEARCH PROJECT YOU MAY CONTACT DR. BERNADETTE CAMPBELL, CHAIR OF THE ETHICS BOARD AT 6135202600 EXT.2517 OR ETHICS@CARLETON.CA. 


\section{Appendix C: Interview Questions}

\section{Interview Questions}

1. What does sexual orientation mean to you?

a). Do you consider it to be fluid?

2. Define what sex means to you

a). Define what kink means to you

3. Do you consider kinky activities sexual? Why or why not?

4. At what age where you aware of your kinky desires?

5 . Did this differ from the age you were aware of your sexual orientation?

6. How does your sexual orientation and kink orientation play with each other?

7. Do you think kink is a sexual orientation?

8. What benefits do you think there are to considering kink a sexual orientation?

9. What disadvantages do you think exist?

10. Have you faced discrimination due to your kinky practises?

11. How open are you about your kinky practises? Who are you open with? Who do you hide this from?

12. Do you feel that kink is a core part of your identity? Why or why not?

13. Is there anything else you would like to add or discuss? 


\section{Appendix D: Informed Consent Form}

Canada's Capital University

Informed Consent Form
Department of Women's and Gender Studies

1401 Dunton Tower, 1125 Colonel By Drive

Ottawa, Canada K1S 5B6

You are invited to participate in a study titled Born this Way? Is Kink a Sexual Orientation? The purpose of this study to determine whether kink should be considered a sexual orientation and the benefits or detriments of such. This study is being conducted by Caitlin Hart (sole researcher) as part of her fulfillment of her masters in Women's and Gender Studies, she can be reached at caitlinhart@cmail.carleton.ca. This project is under the supervision of Dr. Ummni Khan, who can be reached at ummni.khan@carleton.ca if any questions or concerns arise.

\section{Information}

The purpose of this study is explore whether those who self identify as kinky think that kink itself should be considered a sexual orientation. This may involve asking questions regarding your definitions of sexual orientation, kink, and sex. Further discussion could entail what you perceive as the benefits or detriments of defining kink as a sexual orientation. My goal is to construct a better framework potentially for further research regarding this question.

Data Collection (Interview)

By agreeing to participate in this project you are agreeing to partake in an interview in person led my me, Caitlin Hart. These interviews will be semi-structured and will centred around your views on sexual orientation and kink. You are not required to answer all questions and may leave at any time.

\section{Confidentiality and Security}

Anonymity is important to the researcher and will be respected throughout the study. To achieve this pseudonyms will be randomly assigned. Your legal name and/or community pseudonym will not be disclosed to any others during or after the research. Only the lead researcher and supervisor will have access to recordings taken during the interviews, only committee members and my supervisor will have access to transcripts from the interviews.

The information collected during interviews will be encrypted and stored on a password protected computer and back up hard drive. Physical documents will be stored in a locked 
cabinet. No cloud based storage devices will be used. The data may be used in the future for related projects pertaining to kink as a sexual orientation in the form of blogs, books, conference presentations, speaking engagement, and journal articles. The data will only be used for projects that support the purpose stated above.

Risks

Due to the sensitive nature of the topic I will be asking participants to answer questions pertaining to intimate information, that is often considered private. There are potential psychological risks to answering some of these questions. To account for this participants can stop at anytime, I will also provide resources for support and crisis services if this should arise. Participants are not required to share any information that may cause them distress or are not comfortable sharing.

\section{Benefits}

Participants will be sharing potentially useful information for future research regarding the intersection between kink and sexual orientation. Their participation will give voice to a community which is often researched from an outside perceptive and lacks their voice. This information may directly or indirectly help reduce stigma. This research could also contribute to giving BDSM practitioners more protection under the Human Rights Code against discrimination.

\section{Contact}

If you have any questions, comments or concerns during the study you may contact the researcher Caitlin Hart at caitlinhart@cmail.carleton.ca or her supervisor Ummni Khan at ummni.khan@carleton.ca. This research was reviewed by the Carleton Research Ethics Board and has received ethics clearance (REB \# ) until (date). If you feel you have not been treated according to the description in this form, or your rights have been violated during the course of this research project you may contact Dr. Bernadette Campbell, Chair of the Ethics Board at 6135202600 ext.2517 or ethics@carleton.ca.

Feedback and Publication

The research results from this project may be published in the following ways: dissertation, conference presentation, journal articles or book chapters, books, blogs, or articles.

As a participant in this study you have the right to withdraw within a month after their interview has taken place. After this time the participant will not be able to withdraw from the study. If a participant decides to withdraw all their data including consent forms, audio recordings and notes will be destroyed.

\section{Consent}


Do you consent to being recorded with a digital voice recorder during the interview? $\quad \mathrm{Y} N$

Do you consent to follow up contact for follow up questions up to 6 months after you interview?

$$
\text { Y N }
$$

Do you consent to anonymous direct quotations from the interview being used in the final report?

By singing this document, I can confirm that I have read and understood the above information. I have had the opportunity to ask questions and express any concerns with the researcher. I understand that I may withdraw from the study within a certain time frame. I have received a copy of this form. I give consent to participate in the research project as stated above.

Signature of Participant:

Signature of Researcher:

Date: 


\section{Appendix E: Oral Consent Script}

Hello, my name is Caitlin and I am a Master's student in Women's and Gender Studies at Carleton University. I am under the supervision of Professor Ummni Khan

I would like you to participate in a study called Born this Way? Is Kink a Sexual Orientation? The purpose of this study is to determine whether kink should be considered a sexual orientation and the benefits or detriments of such.

This study involves one 60 minute interview. With your consent, the interview will be audiorecorded. Once transcribed, the audio-recording will be destroyed.

By agreeing to participate in this project you are agreeing to partake in an interview in person led my me, Caitlin Hart. These interviews will be semi-structured and will be centred around your views on sexual orientation and kink. You are not required to answer all questions and may leave at any time. There may be follow up only for the purpose of clarification up to one month after the interview has taken place.

Anonymity is important to the researcher and will be respected throughout the study. To achieve this pseudonyms will be randomly assigned. Your legal name and/or community pseudonym will not be disclosed to any others during or after the research. Only the lead researcher and supervisor will have access to recordings taken during the interviews, only committee members and my supervisor will have access to transcripts from the interviews.

The information collected during interviews will be encrypted and stored on a passwordprotected computer and back up hard drive. Physical documents will be stored in a locked cabinet. No cloud based storage devices will be used. The data may be used in the future for related projects pertaining to kink as a sexual orientation in the form of blogs, books, conference presentations, speaking engagement, and journal articles. The data will only be used for projects that support the purpose stated above.

If you would like a copy of the finished research project, please let me know. I will then provide you with an electronic copy.

If you have any questions, comments or concerns during the study you may contact the researcher Caitlin Hart at caitlinhart@cmail.carleton.ca or her supervisor Ummni Khan at ummni.khan@carleton.ca. This research was reviewed by the Carleton Research Ethics Board and has received ethics clearance (REB \# 109375) until September 30, 2019. If you feel you have not been treated according to the description in this form, or your rights have been violated during the course of this research project you may contact Dr. Bernadette Campbell, Chair of the Ethics Board at 6135202600 ext.2517 or ethics@carleton.ca.
Do I have your permission to begin: __ Yes No (If no, thank them for their time.)
Do you agree to be audio-recorded: ___ Yes No 
Do you consent to follow up contact for follow up questions up to 1 month after you interview? Y N

Do you consent to anonymous direct quotations from the interview being used in the final report? Y N

Date:

Participant's name/Pseudonym/Initials:

Researcher's Signature: 


\section{Appendix F: Fetlife Communications}

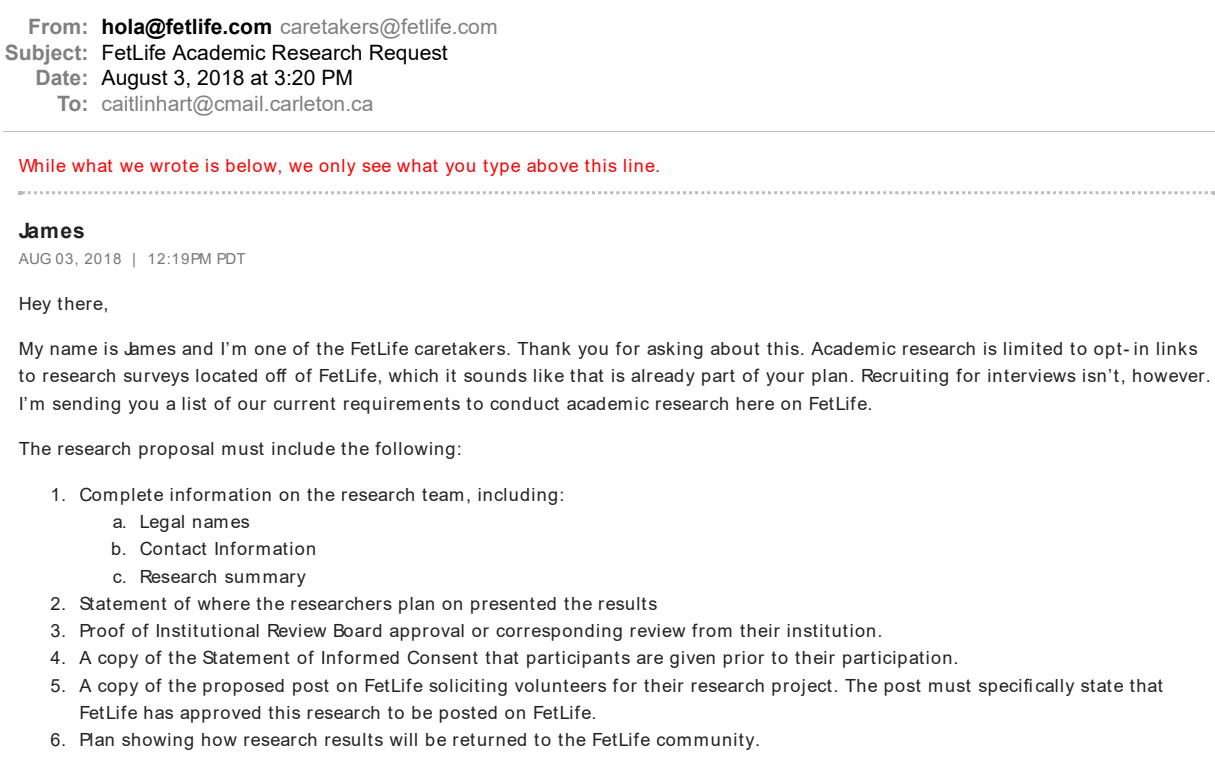

Once we have that information, we'll review the proposal and let you know. I hope that helps. If you have any other questions, please let us know.

Regards,

James

How well did we satisfy you?;- )

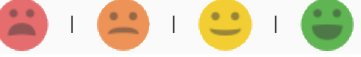

Caitlin

AUG 03, 2018 | 09:51AM PDT

Original message

Hello,

I am a masters student starting a research project concerning whether or not kink should be considered an orientation. For my project I will be conducting interviews and surveys and would like to be able to post material for recruitment on Fetlife. I am wondering if

there is a certain procedure or requirements to do so.

Thank you kindly,

Caitlin

For your reference this is Case \#: 1474842 


\section{Bibliography}

Ahmed, S. (2006). Orientations: Toward a Queer Phenomenology. GLQ: A Journals of Lesbian and Gay Studies, 12:4, 543-574.

American Psychiatric Association. (2013). Diagnostic and Statistical Manual of Mental Disorders: DSM-5. American Psychiatric Association: Washington, D.C.

Arksey, H., \& Knight, P. (1999). Interviews for social scientists. London, UK: Sage Publications.

Bauer, R. (2008) Transgressive and Transformative Gendered Sexual Practices and White Privileges: The Case of the Dyke/Trans BDSM Communities, Women's Studies Quarterly, $36: 3 \& 4,233-253$.

Bauer, R. (2010). Non - monogamy in queer BDSM communities: Putting the sex back into alternative relationship practices and discourse. In M. Barker, \& D. Langdridge (Eds.), Understanding non - monogamies (pp. 142-153). New York: Routledge.

Better, A. \& Simual, B. (2015). How and for whom does gender matter? Rethinking the concept of sexual orientation. Sexualities, 18(5/6), 665-680.

Bezreh, T., Weinberg, T.S., \& Edgar, T. (2012). BDSM Disclosure and Stigma Management: Identifying Opportunities for Sex Education. American Journal of Sexuality Education, 7:1, $37-61$.

Brame, G., Brame, W., \& Jacobs, J. (1993). Different Loving: The World of Sexual Dominance and Submission. Villard Books.

Braun, V., \& Clarke, V. (2006). Using thematic analysis in psychology. Qualitative Research in Psychology, 3(2), 77-101. 
Bridges, D. (2001). The ethics of outsider research. Journal of Philosophy of Education. 35(3), 371- 386.

Brotto, L.A., Yule, M. (2017) Asexuality: Sexual Orientation, Paraphilia, Sexual Dysfunction, or None of the Above?. Arch Sex Behaviour. 46, 619-627.

Brown, T. O. L. (2010). If someone finds out you're a perv (Master's thesis). Retrieved from OhioLINK ETD Center. (Document number: ohiou1279225927).

Bryman, A. (2012). Social research methods (4th ed.). New York, NY: Oxford University Press. Butler,J. (1993). Imitation and Gender Insubordination. In H. Abelove et al. (Eds), The Lesbian and gay studies reader. (pp. 307-320). Routledge.

Callis, A. (2016). Beyond bi: Sexual fluidity, identity, and the post-sexual revolution. In N. L. Fischer \& S. Seidman (Eds.), Introducing the new sexuality studies. (pp. 215-224). New York, NY: Routledge.

Cartwright, Richard L. (1968). "Some Remarks on Essentialism". The Journal of Philosophy. 65 (20): 615-626. doi:10.2307/2024315. JSTOR 2024315.

Charmaz, K. 2006. Constructing Grounded Theory. A Practical Guide through Qualitative Analysis. Londra: Sage Publications Ltd.

Connolly, P.H. (2006). Psychological functioning of bondage/ domination/sado-masochism (BDSM) practitioners. Journal of Psychology \& Human Sexuality,, 18(1), 79-120. http://dx.doi.org/ 10.1300/J056v18n01_05

Cossman, B. (2020, January). \#MeToo, Sex Wars 2.0 and the Regulation of Sexual Harm. Paper presented as part of JurisTalks at Carleton University, Ottawa, ON.

Craene, V. D. (2017). Fucking geographers! Or the epistemological consequences of neglecting the lusty researcher's body. Gender, Place \& Culture, 24(3), 449-464. 
Dancer, P., Kleinplatz, P., \& Moser, C. (2006). 24/7 SM Slavery. Journal of Homosexuality, $50: 2-3,81-101$.

Dekosky, S., Ikonomovic, M., Gandy, S., \& DeKosky, S. (2010). Traumatic brain injury-football, warfare, and long-term effects. The New England Journal of Medicine, 363(14), 1293-1296. https://doi.org/10.1056/NEJMp1007051.

Diamond, L. (2008). Sexual Fluidity: Understanding Women's Love and Desire. Harvard University Press: Cambridge.

Diamond, L. (2012). The Desire Disorder in Research on Sexual Orientation in Women: Contributions of Dynamical Systems Theory. Archives of Sexual Behavior, 41, 73-83. Diamond, L. (2016). Stability of Sexual Attractions Across Different Timescales: The Roles of Bisexuality and Gender. Archives of Sexual Behavior, 46(1), 193-204.

Dymock, A. (2012). But Femsub is broken too! On the normalisation of BDSM and the problem of pleasure. Psychology \& Sexuality, 3:1, 54-68.

Faccio, E., Casini, C., \& Cipolletta S. (2014) Forbidden games: the construction of sexuality and sexual pleasure by BDSM 'players.' Culture, Health \& Sexuality, 16:7, 752-764.

Gemberling, T., Cramer, R., \& Miller, R. (2015). BDSM as Sexual Orientation: A Comparison to Lesbian, Gay, and Bisexual Sexuality. Journal of Positive Sexuality, 1, 56-62.

Goodman, L. A. (1961). Snowball sampling. Annals of Mathematical Statistics, 32, 148-170.

Gulli, C. (2011). The damage done: Sidney Crosby is a case study in what we know, and what we don't know about concussions--and whether anyone can escape their long-term effects.(HEALTH). Maclean's, 124(5).

Hainsworth, J. (2008). Court Rules BDSM case can be heard. Daily Xtra April 22, 2008, https://www.dailyxtra.com/court-rules-bdsm-case-can-be-heard-15982. 
Halley, J. (1993-94). Sexual Orientation and the Politics of Biology: A Critique of the Argument from Immutability. Stanford Law Review, 503.

Hebert, A \& Weaver, A. (2014). An Examination of Personality Characteristics Associated with BDSM Orientations. The Canadian Journal of Human Sexuality, 23:2, 106-115.

Hebert, A., \& Weaver, A. (2015). Perks, problems, and the people who play: A qualitative exploration of dominant and submissive BDSM roles. Canadian Journal of Human Sexuality, 24(1), 49-62. https://doi.org/10.3138/cjhs.2467.

Hill, C. E., Thompson, B. J., \& Williams, E. N. (1997). A guide to conducting consensual qualitative research. The Counseling Psychologist, 25(4), 517-572.

Hubbard, R \& Wald, E. (1994). Gay Genes? In Ruth Hubbard (Eds.), Profitable Promises: essays on women, science, and health (83). Common Courage Press.

Iannotti, L. (2014). I didn’t Consent to That: Secondary Analysis of Discrimination Against BDSM Identified Individuals. CUNY Academic Works.

Katz-Wise S. (2015). Sexual fluidity in young adult women and men: associations with sexual orientation and sexual identity development. Psychology and Sexuality,6(2), 189208.

Keenan, J. (2013). We're Kinky Not Crazy. Slate March 8, 2013, Retrieved from: https://slate.com/technology/2013/03/sexual-kinks-in-the-dsm-v-paraphilic-disordersdescribe-unhappy-kinksters.html.

Khan, U. (2014). Vicarious Kinks. University of Toronto Press.

Khan, U. (2015). In Sickness and in Health: Competing Claims for Science, Social Science, and Culture. Current Sex Health Rep, 7, 49-58. 
Khan, U. (2017). Fetishizing Music as Rape Culture. Studies in gender and sexuality, 18(1),1930.

Kinsey A., Pomeroy, W.B., and Martin ,C.E. (1948) Sexual Behaviour in the Human Male. Philadelphia, PA: WB Saunders Company.

Kleinplatz, P. (2006). Learning from Extraordinary Lovers. Journal of Homosexuality, 50:2-3, $325-348$.

Klesse, C. (2014). Polyamory: Intimate practice, identity or sexual orientation? Sexualities, $17: 1 / 2,81-99$.

Knox, S., \& Burkard, A. W. (2009). Qualitative research interviews. Psychotherapy Research, 19(4-5), 566-575.

Krafft-Ebing, R. (1965). Psychopathia sexualis with especial reference to the antipathic sexual instinct: A medico-forensic study. New York, NY: Special Books.

Luksic, N. (Producer). (2015, February 26). CBC Ideas. [Audio Podcast]. Retrieved from https://www.cbc.ca/radio/ideas/consent-to-harm-part-2-1.2973333.

Martinson, R. (1994). Sexual Orientation: The History and Significance of an Idea. World \& World, 24(3).

Meeker, C. (2013). "Learning the ropes": An exploration of BDSM stigma, identity disclosure, and workplace socialization. In M. S. Plakhotnik \& S. M. Nielsen (Eds.), Proceedings of the $12^{\text {th }}$ Annual South Florida Education Research Conference (pp. 134-141). Miami: Florida International University. Retrieved from http://education.fiu.edu/research_conference/ Miletski, H. (2017). Zoophilia: Another Sexual Orientation? Archive of Sexual Behavior, 46, 3942. 
Morgan, J. (2018). Out of the ring: boxing and long-term brain damage. The Lancet Neurology, 17(10), 848-848. https://doi.org/10.1016/S1474-4422(18)30150-9

Moser, C, \& Kleinplatz, P. (2006). Introduction. Journal of Homosexuality, 50:2, 1-15.

Moser C. (2011). Yet another paraphilia definition fails. Arch Sex Behav. 40(3):483-5

Moser, C. (2016). Defining Sexual Orientation. Archives of Sexual Behaviour, 45, 505-508.

Newmahr, S. (2008). Becoming a sadomasochist: Integrating self and other in ethnographic analysis. Journal of Contemporary Ethnography, 37(5), 619-643

https://doi.org/10.1177/0891241607310626.

Newmahr, S. (2010). Rethinking Kink: Sadomasochism as Serious Leisure. Qual Sociol, 33, 313-331.

Newmahr, S. (2011). Playing on the Edge, Sadomasochism, Risk, and Intimacy. Indiana University Press.

Pascoal, P.M., Cardoso, D., \& Henriques, R. (2015). Sexual Satisfaction and Distress in Sexual Functioning in Sample of the BDSM Community: A Comparison Study Between BDSM and Non-BDSM Contexts, Journal of Sexual Medicine, 12, 1052-1061.

Patton, M. Q. (2015). Qualitative research \& evaluation methods. Thousand Oaks, CA: Sage Publications.

Rehor, J. E. (2015) Sensual, Erotic, and Sexual Behaviors of Women from the "Kink" Community, Archives of Sexual Behavior, 44, 825-836.

Reid, C., Greaves, L., \& Kirby, S. (2017). Experience Research Social Change: Critical Methods, Third Edition. University of Toronto Press.

Ritchers, J., de Visser, R. O., Rissel, C.E., Grulich, A., \& Smith, A. (2008) Demographic and Psychosocial Features of Participants in Bondage and Discipline, "Sadomasochism" or 
Dominance and Submission (BDSM): Data from a National Survey, Journal of Sexual Medicine, 5, 1660-1668.

Sell, R. (1997) Defining and Measuring Sexual Orientation: A Review. Archives of Sexual Behavior, 26 (6).

Seidman, I. E. (1991). Interviewing as qualitative research: A guide for researchers in education and the social sciences. New York, NY: Teachers College Press.

Simula, B. L. (2012) Does Bisexuality ‘Undo’ Gender? Gender, Sexuality, and Bisexual Behavior Among BDSM Participants, Journal of Bisexuality, 12:4, 484-506.

Simula, B. (2019a). A 'different economy of bodies and pleasures'?: Differentiating and evaluating sex and sexual BDSM experiences. Journal of Homosexuality, 66(2), 209-237. https://doi.org/10.1080/00918369.2017.1398017.

Simula, B.L. (2019b). Pleasure, power, and pain: a review of the literature on the experiences of BDSM participants. Sociology Compass: 13, 1-24.

Sherif, B. (2001). The ambiguity of boundaries in the fieldwork experience: Establishing rapport and negotiating insider/outsider status. Qualitative Inquiry, 7(4), 436-447.

Shively, M., Jones, C., \& De Cecco, J. (1984). Research on Sexual Orientation: Definitions and Methods, Bisexual and Homosexual Identities, Center for Research and Education in Sexuality, San Francisco State University.

Sloan, L. J. (2015). Ace of (BDSM) clubs: Building asexual relationships through BDSM practice. Sexualities, 18(5-6), 548-563. https://doi.org/10.1177/1363460714550907

Smith, M. (2014). Affect and Respectability Politics. Theory \& Event, 17(3) Retrieved from http://search.proquest.com/docview/1628558944.

Sprott,R \& Hadcock,B. (2018) Bisexuality, pansexuality, queer identity, and kink identity, 
Sexual and Relationship Therapy, 33:1-2, 214-232.

Stiles, B. L., \& Clark, R. L. (2011) BDSM: A Subcultural Analysis of Sacrifices and Delights, Deviant Behavior, 32:2, 158-189.

Tripodi, F. (2017). Fifty Shades of Consent? Feminist Media Studies, 17(1), 93-107.

Trudeau: 'There's no place for the state in the bedrooms of the nation' [Video File]. (1967, December 21). Retrieved from https://www.cbc.ca/archives/entry/omnibus-bill-theres-noplace-for-the-state-in-the-bedrooms-of-the-nation.

Tweedy, A. (2011).Polyamory as a sexual orientation. University of Cincinnati Law Review, 79, $1461-1515$.

van der Helm, P. (2016). Structural coding versus free-energy predictive coding. Psychonomic Bulletin \& Review, 23(3), 663-677.

Vrangalova,Z.,\& Savin-Williams, R. C. (2012).Mostly heterosexual and mostly gay/lesbian: Evidence for new sexual orientation identities. Archives of Sexual Behavior, 41, 85-101.

Weinberg, M., Williams, C. J., \& Moser, C. (1984). The social constituents of sadomasochism. Social Problems, 31, 379-389. doi:10.2307/800385

Weinberg, T. (2006). Sadomasochism and the social sciences: A review of the sociological and social psychological literature. Journal of Homosexuality, 50(2-3), 17-40. https://doi.org/10.1300/J082v50n02_02.

Weiss, M. (2006). Mainstreaming kink: The politics of BDSM representation in US popular media. Journal of Homosexuality, 50(2-3), 103-132. https://doi.org/10.1300/J082v50n02_06.

Weiss, M. (2011) Techniques of Pleasure: BDSM and the Circuits of Sexuality. Duke University Press. 
Wilton, T. (2004). Sexual (Dis) Orientation: Gender, Sex, Desire and Self Fashioning. New York: Palgrave Macmillan.

Wismeijer, A \& van Assen, M. (2013) Psychological Characteristics of BDSM Practitioners, Journal of Sexual Medicine, 10, 1943-1952.

Wright, S. (2006). Discrimination of SM - identified individuals. Journal of Homosexuality, 50(2-3), 217-231. https://doi.org/ 10.1300/J082v50n02_10.

Wright, S. (2008). Survey of violence and discrimination against sexual minorities, National Coalition for Sexual Freedom, Retrieved from https://secureservercdn.net/198.71.233.68/9xj.1d5.myftpupload.com/wpcontent/uploads/2019/12/Violence-Discrimination-Against-Sexual-Minorities-Survey.pdf.

Wright, S. (2014). Kinky parents and child custody: The effect of the DSM - 5 differentation between the Paraphilias and Paraphilic disorders. Archives of Sexual Behavior, 43(7), 12571258. https://doi.org/10.1007/s 10508 - 013 - 0250 - 6.

Wright, S. (2018). De - pathologization of consensual BDSM. Journal of Sexual Medicine, 15(5), 622-624. https://doi.org/ 10.1016/j.jsxm.2018.02.018.

Yost, M., \& Hunter, L. E. (2012). BDSM practitioners' understandings of their initial attraction to BDSM sexuality: Essentialist and constructionist narratives. Psychology and Sexuality, 3(3), 244-259. https://doi.org/10.1080/19419899.2012. 700028 
